\title{
EFFECTS OF PEDUNCULOPONTINE TEGMENTAL NUCLEUS LESIONS ON MORPHINE-INDUCED CONDITIONED PLACE PREFERENCE AND ANALGESIA IN THE FORMALIN TEST
}

\author{
Mary C. Olmstead \\ Department of Psychology \\ McGill University \\ November, 1991
}

\begin{abstract}
A thesis submitted to the faculty of Graduate studies and Research in partial fulfillment of the requirements for the degree of Master of Arts
\end{abstract}

(c) Mary C. Olmstead, 1991 
TABLE OF CONTENTS

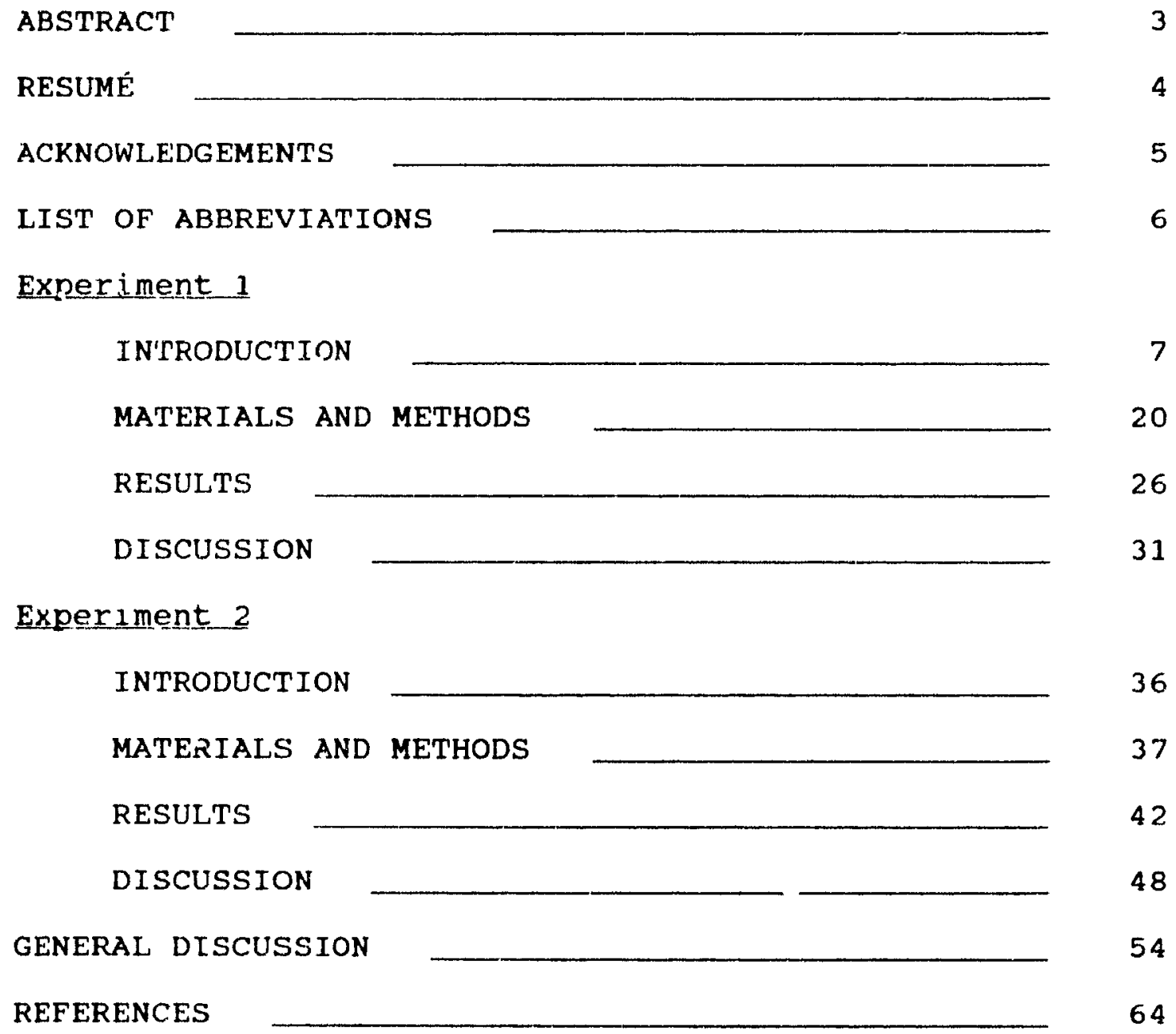




\begin{abstract}
It has been proposed that analgesia in the formalin test is mediated through forebrain systems associated with reinforcement, whereas motor responses necessary for the expression of pain are organized at the level of the brainstem. Because it is lorated in the brainstem and connected with both limbjc reward systems and motor structures, the peduncu-opontine tegmental nucleus (PPTg) is a site where reward signals might influence the expression of pain. Experiment 1 confirmed that NMDA-induced lesions of the PPTg block the development of a conditioned place preference to morphine. Subsequently, morphine-induced analgesia was found to be reduced, but not eliminated. The reduction of reward was not significantly correlated with loss of choline acetyitra.ıferase containing neurons in the PPT'. In Experiment 2, PPTg lesions did not affect morphine analgesia in drug naive animals, but produced motor abnornalities and blocked the morphine-induced depression of sponta.roous motor activity and catalepsy.
\end{abstract}




\section{RESIIMÉ}

It a eté proposé que l'anal gésie observée dans le tast de formaline est produite par les systems du télencéphale qui sont associés avec le renforcement, alors que les réponses moteures necessaires à l'expresision de la douleur sont organisées au niveau du mésencéphale ou plıpart. Le nucleus tegementi pedunculopontinus (PPTg) dû à sa position dans le mésencéphale et à ses connection: avec les systemes de récompenses peuvent influencer l'explession de la douleur. La première expérience a confirmé que leis lésions produites par le NMDA au PPTg bloquent le développenent d'une préférence positionelle conditionée à la morphine. Par après, l'analgésie produite par la morphine était réduite mais pas éliminée. La réduction de la récompense n'était pas corréliee de façon significative avec la perte de neurones contenant de la choline acetyltransferase dans le PPTg. Dans la deuxième expérience, les lésions au PPTg n'ont pas affectés l'agent analgesique de la morphine chez des animaux jamais drogués, mais par contre ces lésions ont produit des abnormalités du mouvement et ont bloqués la dépression de l'activité motrice spontanée et de la catalepsie produite par la morphine. 
ACKNOWLEDGEHENTS

I would like to thank the following individuals for their assistance: Janet Raymond for technical assistance, Frederic Vallée-Tourangeau for french translation of the abstract, Leslie Farquharson for proof reading the maunuscript, Dr. Noboru Hiroi for discussion of the text, and particularly Dr. Keith Franklin for his constant support, encouragement, and expertise. 


\section{LIST OF ABBREVIATIONS}

\begin{tabular}{|c|c|}
\hline $5-\mathrm{HT}$ & serotonin \\
\hline 6-OHDA & 6-hydroxydopamine \\
\hline $\mathrm{ACh}$ & acetylcholine \\
\hline ChAT & choline acetyltransferase \\
\hline CPP & conditioned place preference \\
\hline $\mathrm{DA}$ & dopamine \\
\hline ICSS & intra-cranial self-stimulation \\
\hline MLR & mesencephalic locomotor revion \\
\hline NA & nucleus accumbens \\
\hline NADPH & nicotinamide adenine dinucleotide phosphate \\
\hline NE & norepinephrine \\
\hline NMDA & N-methyl-D-asparate \\
\hline NMR & nucleus raphe magnus \\
\hline PAG & periacqueductal grey \\
\hline PPTg & pedunculopontine tegmental nucleus \\
\hline RVM & rostral ventromedial medulla \\
\hline SMA & spontaneous motor activity \\
\hline SN & substantia nigra \\
\hline VP & ventral pallidum \\
\hline VTA & ventral tegmental area \\
\hline
\end{tabular}




\section{Experiment 1}

\section{INTRODUCT ION}

Experiences of pleasantness and unpleasantness and the:r role in motivatirig behaviour have been studied for centuries. The Greek philosopher Epicurus (341-270 B.C.) emphasized that happiness could be achieved through the pursuit of pleasure and the avoidance of pain. In the nineteenth century, spencer (1872) speculated that pain and pleasure are the principla guiding forces that motivate human behaviour. Using spencer's hypothesis as a basis, Troland (1928) classifled stimuli according to their sensory properties and attempted to relate hedonic experiences to sensation. Beebe-center (1932) also examined sensory pe:ception and suggested that experiences of pleasantness and unpleasantness are opposite extremes on a single intensity continuum. Recently Le Magnen et al. (1980) reformulated this suggestion in physiological terms and proposed that reward and pain modulation are medlated through the same neural substrate; when the system is activated so that rewarding effects are enhanced, pain will simultaneously be diminished.

Le Magnen's hypothesis is supported by evidence: indicating that responses to aversive stimuli are altered by changes in levels of motivation for other goals. For example, food deprivation reduces the threshold to nociceptive stimuli (McGivern and Bentson, 1980) and sucrose infusions into mouths of infart rats increase pain thresholds (Blass et a1., 1987). 
Moreover, there is evidence that an animal may react to noxious stimuli by attempting to activate endogenous reward systems. Ingestion of highly palatable foods is increased under stressful conditions (Antelman et al., 1975, 1976; Levine et al., 1982) and, responding for intra-cranial selfstinulation (ICSS) (believed to reflect the activation of endogenous reward substrates) is faciljtated by both footshock (De witte, 1979) and aversive hindbrain stimulation (Carr and Coons, ?982).

Le Magnen's hypothesis further proposes that the biochemical mechanisms mediating reward and pain modulation both involve endogenous opioid systems. In support of this suggestion, Levine et al. (1982) demonstrate that the opiate antagonist naloxone blocks both feeding and analgesic responses elicited by tail-pinch, and Roane and Martin (1990) report that morphine analgesia is increased following continuous sucrose feeding. Furthermore, naloxone enhances a taste aversior and abolishes a taste preference (Le Magnen et al., 1980). These findings imply that pleasurable and aversive sensations may be ascociated with high and low opioid activity respectively.

The mechanism(s) by which reinforcing stimuli alter(s) endogerous opioid mechanisms and morphine analgesia are unknown. Roane and Martin (1990) suggest that the properties of sucrose which make it a reinforcing stimulus, may be related to those responsible for its modulation of opioid 
function. Similarly, Carr (1784) hypothesizes that opiates; potentiate reward through activation of oploid systems while concurrently dimjnishing emotional responsiveness to aversive stimuli. These hypotheses are also consistent with the notion that reward and analgesia may be mediated through the activation of a single neural substrate.

The idea that reward and analgesia are both reflections of the state of activity in common systems provides a neurochemical mechanism for the pschological hypothesis that analgesia is associated with a change in the emotional response to pain. For example, it has been suggestea that opiods may produce their analgesic effect by reducing the patient's suffering, but not the sensory intensity of their pain (Beecher, 1959; Jaffe and Martin, 1975). Consistent with this view, all strong, centrally acting, analgesics are selfadministered by both animals and humans (Franklin, 1989), and their efficacy as analgesics is roughly proportional to their abuse potential. Thus, the most powerful analgesics, including morphine, heroin, and amphetamine, have high abuse potential, while the partial agonist analgesics have weaker analgesic activity, but reduced abuse potential (Jaffe and Martin, 1975). Since opioid receptors are widely distribuiced in the brain, the coincidence of analgesic activity and rewarding effects of opiods is not itself strong evidence that reward and analgesia are mediated through a single neural substrate. stronger support for the hypothesis would be evidence that the 
opioid receptors subserving analgesia are located in the same areas as those subserving reward and interact in the same way with the neurotransmitter systems involved in reward.

The neural substrate, of reward have been explored using ICSS, self-administration, and conditioned place preference (CPP) paradiyms. Based on converging evidence from studies employing these paradigms, Koob and Bloom (1988) propose that neural structures and systems mediating the reinforcing effect of drugs include DA neurons in the ventral tegmental area (VTA), iWise and Bozarth, 1987), cell bodies in the nucleus accumbens (NA) (Zito et al., 1985), and termination sites of NA fibers in the the ventra) pallidum (VP) (Swerdlow et al., 1984; Hubner and Koob, 1987).

Much of the evidence on neurochemical mechanisms of reinforcement has been derived from the CPP paradigm, which, as a measure of reward, has a number of advantages (Carr et al., 1989). First, the CPP paradigm is very sensitive: rewarding effects are observed at $0.08 \mathrm{mg} / \mathrm{kg}$ morphine (Mucha et al., 1982), $0.5 \mathrm{mg} / \mathrm{kg}$ d-amp (Spyraki et al., 1982b), or 0.08 $\mathrm{mg} / \mathrm{kg}$ heroin (Spyraki et al., 1983); CPP can be produced using a sirgle drug pairing (Mucha et al., 1982); CPP can be retained for up to one month following three morphine pairings in a distinct environment (Mucha and Iversen, 1985). Second, testing is conducted under drug free conditions, thus eliminating confounds of sensory and/or motor changes that may influence responding. Finally, drug dose is determined and 
controlled by the experimenter, unlike self-administration paradigms in which the animal's rate of responding determines the dose administered.

Studies employing the CPP paradigm occasionally yield different results from those using self-adminstration as a measures of reward. For example, 6-hydroxydopamine (6-OHI)A) lesions of the NA block cocaine self-adminstration (Roberts et al., 1980), but do not affect cocaine-induced CPP (Spyraii ct al., 1982a), and 6-OHDA lesions of the NA block heroin-induced CPP (Spyraki et al., 1983), whereas responding for heroir self-administration is not affected (Petit et al., 1984). Carr et al. (1989) points out that these apparently contradictory results may be due to different sensitivities of the paradigms to the reinforcing effects of drugs, and further suggests that the number of discrepant findings are relatively few in comparison with the vast majority of casas in which the two methods have generated conceptually consistent results. This fact, along with the advantages outlined above, suggests that the CPP paradigm has considerable concurrent validity as a measure of reward (van der Kooy, 1987; Carr et al., 1989).

The assessment of an affective component of pain in animals is more problemati $=$. There are more than 50 pain tests recorded in the literature (Franklin and Abbott, 1989), but the most commonly used tests would not be expected to be sensitive to the affective aspects of pain because they measure latencies of refexes to a nociceptive stimulus at the 
pain threshold. Since the reflex rapidly terminates the stimulus, it is unlikely that a signif:cant affective response is evoked by the nociceptive stilnlus. In this regard, carroll and Lim (1960) have shown that, when nociceptive stimulation is continued beyond the latency of the withdrawal reflex, affective responses to pain are evoked and these responses involve nigher levels of the nervous system than the reflex withdrawal responses to a noxious stimulus which are organized in the spinal cord.

one test that measures responses to continuing pain is the formalin test. Developed by Dubuisson and Dennis (1977) as an animal model of clinical pain, the procedure involves injecting of a small quantity $(0.05 \mathrm{ml})$ of dilute formalin into the animal's paw and assessing its protective responses towards the injured $1 \mathrm{imb}$. Human subjects who have experienced the pain of formalin injection describe it as initally burning in quality, then developing into a deep aching pain that recedes over 90 minutes. At its peak, the pain is moderate in intensity, poorly localized, and the primary area is surrounded by a region of hyperasthesia and mild spontaneous pain (Franklin and Abbott, 1989).

It has been shown that the formalin test is sensitive to analgesic mechanisms that are different from those predominant in reflex withdrawal tests (Abbott et a1., 1982; Abbott and Melzack, 1982; Abbott and Melzack, 1983; Ryan et al., 1985; Morgan and Franklin, 1990). For example, tolerance to morphine 
analgesia develops rapidly in threshold tests, but not the formalin test (Abbott et al., 1981). Further evidence suggests that antinociception in threshold tests and analgesia in the formalin test are not mediated through the same neural system. As reviewed by Frields (1991), opioid analgesics are thought to activate opioid receptors the periacqueductal grey (PAG). PAG fibers project to the rostral ventromedial medul la (RVM), which in the rat, includes the nucleus raphe magnus (NRM), the nucleus reticularis gigantocellularis, and the nucleus reticularis paragigantocellularis. RVM neurons descend through the dorsolateral funiculus to the dorsal horns of the spinal cord where sensory input is inhibited. Lesions of the NRM and caudal PAG attenuate morphine analgesia in the tail flick test, but have no effect in the formalin test (Abbott at a1.. 1982; Abbott and Melack, 1983; Ryan et al., 1985). The same lesions attenuate the analgesic effects of PAG stimulation in the tail flick test, but not the formalin test (Abbott et al., 1982). Moreover, dorsolateral funiculus lesions attenuáte morphine analgesia in the tail flick test but have no effert on analgesia in the formalin test (Ryan et al., 1985).

Pharmacological mechanisms of analgesia in the two tests are also dissociable. Serotonin antagonists potentiate morphine analgesia in the formalin test but attenuate the effect in the tail flick tests (Dennjs and Melrack, 1980; Abbott and Melzack, 1982; F'asmer et al., 1986). Abbott and Young (1989) have recently shown that morphine analgesia in 
the formalin test is potentiated by decreasing, and attenuated by increasing, serotonin (5-HT) synthesis. In addition, norepinephrine (NE) antagonists attenuate morphine analgesia in the formal in test and potentiate morphine analgesia in the tail flick test (Dennis et al., 1980; Tchakarov et al., 1985). Finally, recent evidence suggests that DA systems ascending from the VTA mediate analgesia in the formalin, but not the tail flick, test (Lin et al., 1989; Franklin, 1989; Morgan and Fra'ıklin, 1990).

The evidence outlined above indicates that analgesia in the formalin test is not mediated through the system outlined by Fields (1991). Rather, forebrain structures appear to be responsible for the effect because lesions of the median raphe, which projects rostrally to forebrain structures (Conrad et al., 1974), have no effect on the tail flick test (Abbott and Melzack, 1982; Buxbaum et al., 1973), but potentiate morphine analgesia in the formalin test (Abbott and Melzack, 1982). In addition, microinjections of morphine into the lateral ventricles (Cohen et al., 1984), lateral habenula, dorsal thalamic region (Cohen and Melzack, 1985), VTA and NA (Franklin, 1989; Morgan and Franklin, 1990) as well as stimulation of the habenula (Cohen and Melzack, 1986) produce analgesia in the formalin test. Finally, morphine analgesia in the formalin test is potentiated by psychomotor stimulant activation of ascending DA projections, originating in the 
VTA, and attenuated by destruction or pharmacological blockade of this system (Lin et al., 1989; Morgan and Franklin, 1991).

There is some evidence suggesting neural substrates mediating the reinforcing effects of drugs and analgesia in the formalin test overlap (Franklin, 1989; Lin et al., 1989). For example, microinjections of morphine into the lateral habenula, as well as stimulation of this region, produce analgesia in the formalin test (Cohen and Melzack, 1985; Cohen and Melzack, 1986). Stimulation of the habenula is also rewarding as shown by the fact that ICSS in the region is vigorous (Sutherland and Nakajima, 198i). Furthermore, ascending DA projections from the VTA to the NA are important for the reinforcing effects of drugs (Koob and Bloom, 1988) as well as the analgesic effects of morphine (Morgan and Franklin, 1990), amphetamine (Morgan and Franklin, 1991), and cocaine (Lin et al., 1989; Pertovaara et al., 1988) in the formalin test. This evidence suggests that, at the level of the forebrain, drug-induced reinforcement and analgesia may be produced by activation of the same neural system.

Matthies and Franklin (1990) confirm that analgesia in the formalin test is mediated by forebrain structures, and further demonstrate that motor responses necessary for the expression of pain in this test occur at or below the level of the brainstem. They found that responses to a formalin injection were not altered by transections at the level of the rostral metencephalon. Morphine administration, howeve. was 
ineffective in reducing formalin-induced pain responses in these animals. Given these findings, it appears that, in order to produce analgesia in the formalin test, forebrain systems must be capable of modulating nociceptive input at the level of the brainstem.

Because it is located in the brainstem and receives projections from limbic structures associated with reinforcement, the pedunculopontine teqmental nucleus (PPTg) is a possible site wherein reward signals exiting the forebrain might influence brainstem mediated pain. For example, the PPTg receives input from, and projects to, the VTA (Swanson 1982). There is a direct projection from the NA to the PPTg, as well as an indirect connection through the VP (Natua et al., 1978). Swanson et al. (1984) confirm the latter report, tracing the NA inhibitory input to the subpallidal region through the medial forebrain bundle to the PPTg.

In addition to its relationship with the limbic system, the PPTg has strong connections with structures associated with motor systems. These include reciprocal connections with the various basal ganglia structures including the entopeduncular nucleus, substantia nigra (SN) (Moon Edley and Graybiel, 1983; Beninato and Spencer, 1987; Clarke et al., 1987), subthalamic nuclei (Hammond et al., 1983; Hallanger et al., 1987), globus pallidus, and neostriatum (Saper and Lowey, 1982; Jackson and Crossman, 1983; Spann and Grofova, 1989), as well as descending projections to the deep cerebellar nuclei 
(Dellovade et al., 1988; Newman and Ginsberg, 1988), the nucleus reticularis gigantocellularis in the region of the medioventral medulla (Garcia-Rill et al., 1986; Rye et al., 1987; Spann and Grofova, 1989), the pontomedul lary reticular nuclei (Rye et al., 1988), and the spinal cord (Goldsmith and van der Kooy, 1988; Rye et al., 1988; Spann and Grofova, 1989). Based on these observations Graybiel and Ragsdale (1978) and Alexander and Crutcher (1990) propose that the PPTg is one of the subsidiary basal ganglia circuits. Moreover, the PPTg coincides anatomically with the mesencephalic locomotor region (MLR) in the rat (Skinner and Garcia-Ri11, 1984); that is, locomotion call be induced by electrical stimulation of this region following brain stem transection.

Based on the anatomical connections linking the PPTg to limbic and motor structures, Koob and Bloom (1988) propose that the region is a critical site in neural systems mediating the reinforcing properties of drugs. This hypothesis is supported by the finding that lesions of the PPTg block the acquisition of a CPP to both morphine and amphetamine in rats (Bechara and van der Kooy, 1989). The present study was designed to investigate the role of the PPTg in morphine reinforcement and analgesia in the formalin test. If nerual substrates mediating reinforcement and analgesia are isomorphic, there should be a correlation between reduction of the two effects following lesions of the PPTg. The first experiment attempted to replicate Bechara and van der Kooy 
(1989) by examining the development of a morphine-induced CPP in animals with neurotoxin lesions of the PPTg. Following this test, in the same animals, morphine analgesia in the formalin test was evaluated.

There is both anatomical and functional evidence that the PPTg may be involved in pain modulation. PPTg fibers project to the nucleus reticularis gigantocellularis and stimulation of the region suppresses nociceptive input (Fitzgerald and Proudfit, 1989; Haws et al., 1989; Katayama, 1984)). Because the PPTg has been implicated in nociceptive modulation in reflex withdrawal tests, (Haws et al., 1989; Katayama et al., 1984), the present study also tested whether the distinction between systems mediating analgesia in threshold and formalin tests is maintained at this brainstem nucleus.

The study further attempted to identify the neurosransmitter(s) within the PPTg responsible for mediating morphine reinforcement and/or anaigesia. There has been considerable controversy concerning which neural regions constitute the PPTg. The term was originally employed by Olszewski and Baxter (1954) to describe the region of the human mesencephalic tegmentum which is bound medially by the superior cerebellar peduncle, laterally and ventrally by fibers of the medial lemniscus, and dorsally by the nuclei cuneiformis and subcuneiformis. Some authors (Rye et al., 1987; Rye et al., 1988; Lee et al., 1988) define the PPTg as a large celled cholinergic nucleus and, based on 
cytoarchitecture, chemistry, and connections, separate it from the medially adjacent midbrain extrapyramidal system. other researchers, however, have identified non-cholinergic cells within the boundaries of the PPTg (Scarnati et al., 1986, 1988; Goldsmith and van der Kooy, 1988; and Kang and Kitai, 1990). According to Spann and Grofova (1989), the definition of the PPTg presented by Rye and colleagues is controversial and urorthodox because a nucleus consists of a cell population within a giver, region irrespective of size, chemistry, or projections. Baised on morphology, transmitter type and electrical membrane properties, Kang and Kitai (1990) identify three different types of neurons within the PPTg; they conclude that both large cholinergic and small non-chol inergic cells constitute the nucleus. The non-cholinergic neurotransmitter in the PPTg has not been identified, al though Clements and Grant (1990) suggest that a sub-population of neurons within the PPIg may be glutamatergic. The present study employed the term PPrg in agreement with the definition of the region in the rat brain described by Newman (1985): that is, the region consists of both cholinergic and noncholinergic neurons within the boundaries outlined above.

In their examination of PPTg mediated reward, Bechara and Van der Kooy (1989) observed a correspondence between the variation in individual PPTg lesions and the degree of motivational deficits. Based on this evidence, they propose that the critical site for psychoactive drug reward is the 
ventromedial PPTg. By comparing their localized lesions to the results of an anatomical tracing study (Goldsmith and Van der Kooy, 1988), they suggest that the most effective block of CPP was associated with lesions of the non-cholinergic regions of the PPTg. Immunocytochemical studies have revealed that much of the PPTg cell volume is made up of acetylcholine (ACh) cells (Newman, 1985; Rye et al., 1988) that can be specifically labelled (Vincent et al., 1983). Therefore, the present study formally tested Bechara and van der Kooy's hypothesis by counting the ACh cells in PPTg lesioned animals and assessing the relationship between cholinergic depletion and the blockage of CPP reward and/or analgesia.

\section{MATERIALS AND METHODS}

subjects

The subjects were 41 ( 21 lesioned and 20 sham lesioned) adult male wistar rats supplied by Charles Rivers, Quebec. Rats weighed between 300 and 350 grams at the start of the experiment. Animals were housed individually, kept on a 12 hours on and 12 hours off 1 ight/dark schedule, and allowed ad libitum access to Purina rat chow and water except during experimental procedures.

\section{Apparatus}

The CPP apparatus consisted of three compartments, made of wood with a plexiglass front wal1. Two of the compartments were identical in size $(45 \times 45 \times 30 \mathrm{~cm})$, but differed in colour, tactile, and olfactory cues. One compartment was 
painted white and had wood chips on a smooth floor. The other compartments was painted black and the floor was made of $12 \mathrm{~mm}$ wire mesh. In addition, a few drops of vinegar ( $1 \mathrm{ml} 2 \%$ acetic acid) were placed on the floor of this compartment below the wire mesh. These two compartments were completely separated from each other by a wooden partition. An entrance to each compartment was located at the rear next to the partition. The third compartment, an unpainted tunnel $(36 \times 18 \times 20 \mathrm{~cm})$, connected the two entrances. This apparatus does not produce any unconditional preference for either compartment (clarke et al., 1990).

Formalin testing was carried out in a clear, plexiglass, cubicle with dimensions $32 \times 32 \times 32 \mathrm{~cm}$. Below the floor, a mirror angled at 45 degrees provided the experimental rater with an unobstructed view of the rat's paw.

surgery

Surgical procedures and post operative care of the animals were carried out in accordance with the guidelines for the ethical use of animals in research approved by the

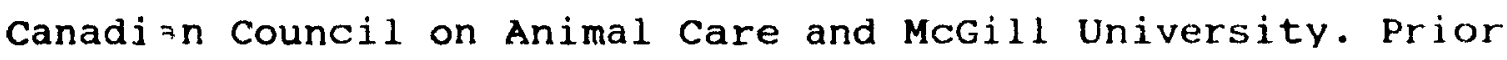
to surgery, animals were anaesthetized with Nembutal (60 $\mathrm{mg} / \mathrm{kg}$ ) and secured in a standard stereotaxic apparatus. Injector needles, inserted through two holes drilled in the skull, were aimed at the region of the PPTg. According to the atlas of Paxinos and Watson (1986), coordinates were $-7.8 \mathrm{~mm}$ posterior to Bregma, $+/-1.6 \mathrm{~mm}$ lateral to the midline, and - 
$7.0 \mathrm{~mm}$ ventral to the skull surface. $0.5 \mathrm{ul}$ of $0.1 \mathrm{M} \mathrm{N}$-methylD-asparate (NMDA) solution or physiological saline (sham lesion) was injected via a 250 ul syringe over ten minutes. The injector was left in place for five minutes following the infusion. Animals were allowed to recover for two weeks following surgery before any testing began. During this time, they were handled for a few minutes each day.

Procedures

Place Conditioning

The CPP procedure required eight days. on day 1 , entrances to the turnels remained opened and rats were allowed to freely explore the three compartments for 30 minutes. On the following six days, each rat received subcutaneous injections of morphine sulphate $(2 \mathrm{mg} / \mathrm{kg})$ or vehicle and was immediately confined to one of the distinct environments. Order of injection and drug-paired environment were counterbalanced within groups. On day 8 , entrances to the tunnel were opened, each rat was placed in the tunnel, allowed a 10 minute period to explore, then tested for 20 minutes by recording the amount of time spent in each of the three compartments.

A balanced paradigm, in which animals show no baseline preference for either compartment, was used for the following reasons: (1) A balanced paradigm measures the positive reinforcing properties of the drug stimulus whereas the unbalanced paradigm may be confounded by interactions between 
various non reinforcing effects of the drug and a preterence for the unconditioned compartment. (2) Unbalanced paradigms often produce relatuve increases in time spent in the least preferred side, not absolute preferences for the drug paired compartment, raking interpretation of the results difticult. (3) Groups can be counterbalanced in the balanced paradigm. (4) Unbalanced paradigms introduce problems of ceiling ef fects (van der Kooy, 1987; Carr et al., 1989).

Formalin Testing

One week after the completion of the CPP test, morphine analgesia was assessed in the formalin test. Formalin testing was based on the procedure described by Dubuisson and Dennis (1977) and modified by Abbott et al. (1984). On the two days prior to testing, rats were placed in the test cubicle for 30 minutes to allow them to habituate to the apparatus and test room. On test day, rats were injected with $0.05 \mathrm{ml}$ of $2.5 \%$ formalin into the plantar surface of one hindpaw. The injection initially produces a moderate pain that lessens or disappears after 5 to 10 minutes, then returns 20 to 30 minutes following the injection and continues steadily for an additional 30 to 60 minutes. Animals that did not demonstrate signs of pain within ten minutes of injection were eliminated from the study. To ensure that the effect of morphine was assessed when pain scores were stable, testing began 30 minutes after the formalin injection and continued for 20 minutes. 
The animal's level of pain was determined according to the following scale: walking or sitting normally, that is, showing no preference for the injected paw (pain rating $=0$ ); favouring the injected paw, that is, not applying full weight while walking or sitting (pain rating $=1$ ); holding the injected paw off the floor (pain rating $=2$ ); licking or chewing the injected paw (pain rating $=3$ ).

The pain score for the entire 20 minutes period was calculated to be the sum of the number of seconds spent in each category multiplied by the pain rating value and divided by 1200 , thus providing a pain score with a possible range of 0.0 to 3.0 . Immediately prior to formalin injection, animals were subcutaneously injected with morphine sulphate $(4 \mathrm{mg} / \mathrm{kg})$. One week later, the test was repeated with an $8 \mathrm{mg} / \mathrm{kg}$ morphine injection.

Histology

Animals were sacrificed with $30 \%$ chloral hydrate and brains were immediately removed and frozen. Coronal sections (20 um) were cut and mounted on gelatin coated slides. Adjacent sections were mounted on alternate series of ' $A$ ' and 'B' slides.

In order to identify cholinergic cells, ' $A$ ' sections were stained using the nicotinamide adenine dinucleotide phosphate (NADPH)-diaphorase histochemical technique described by vincent et al. (1983). Briefly, slices were fixed for 10 minutes in a $0.1 \mathrm{M} / 0.1 \mathrm{M}$ solution of $10 \%$ formalin in Phosphate 
Buffered Saline (PBS) ( $\mathrm{pH}$ 8.0), rinsed twice for five minutes in PBS, incubated at $37 \mathrm{C}$ for 30 minutes in a solution of PBS containing $1.0 \mathrm{mM} \mathrm{NADPH}, 0.2 \mathrm{mM}$ nitroblue tetrazolium, and $0.3 \%$ Triton $\mathrm{x}-100$, rinsed, air dried over night, and coverslipped. Choline acetyltransferase (ChAT) containing neurons stain deep blue and can be easily identified. By combining this technique with immunofluorescence, vincent and colleagues demonstrated that the diaphorase cells in the region of the PPTg are cholinergic.

' $B$ ' sections were stained using the Kluver Barrera method. The location of each lesion was determined according to the atlas of Paxinos and watson (1986). The extent of the lesion was identified on the ' $B$ ' sections by determining the area where cells were lost or gliosis was present. Animals with lesions extending beyond the region of the PPTg to the SN and/or the PAG were not included in the analysis. 'B' sections were also examined to determine the injection site in the sham lesioned animals. Only those animals with injection sites within the boundaries of the PPTg (see below) were included in the analysis.

' $A$ ' sections were examined to determine the proportion of cholinergic depletion within the region of the PPTg. NADPH stained neurons were counted within the boundaries of the PPI'g outlined by Newman (1985): caudally from the caudal substantia nigra and retrorubral field to the fourth cranial motor nucleus and rostral parabrachial nucleus; dorsally from the 


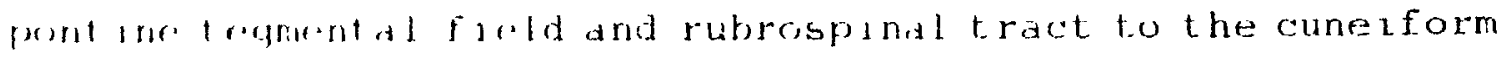
murlous; and laterslly from thes perlacqueductal grey and the deressialion of che brachium conjunctivam to the lateral

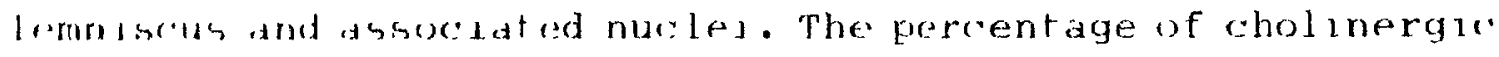
drpleturn in lescuned andmals was assessed by comparing the number of chat rontaneng cells present to that of sham Irasoned animals in the following manner: Irss than 50 of of the chol inerale cells prosent = extensive lesion; $50 \%$ to $75 \%$ of I ho "holerirguc cells present = partlal lesion; animals with more 1 han $75 \%$ of the cholineryld cells present were discarded from the study. Bastod on this criterion, lesioned animals were divider ento lwe ategories.

Stat ast wal inalysis

('pl) data and pain scores la the formalin test were And lyad using it repeated measures 2-way ANOVA with group as one ractor and compartment in the comlitioning apparatus (CPP) (1) druy dose (formalin test) as the other factor. Palrwise comprosuns for both tests were analyzed using Tukey's Hotertod $T$ test. Dose response curves were obtained in tho formalin test by plotting mean pan score against dose. The Mrlom fur signjfirance in both tests was $p<0.05$.

\section{RESULTS}

Histology

'The location and extent of the largest (solud circle) and smal lest (dotted circle) PPTg lesions are shown in figure 1. cha'l containing vells were counted within the boindaries 


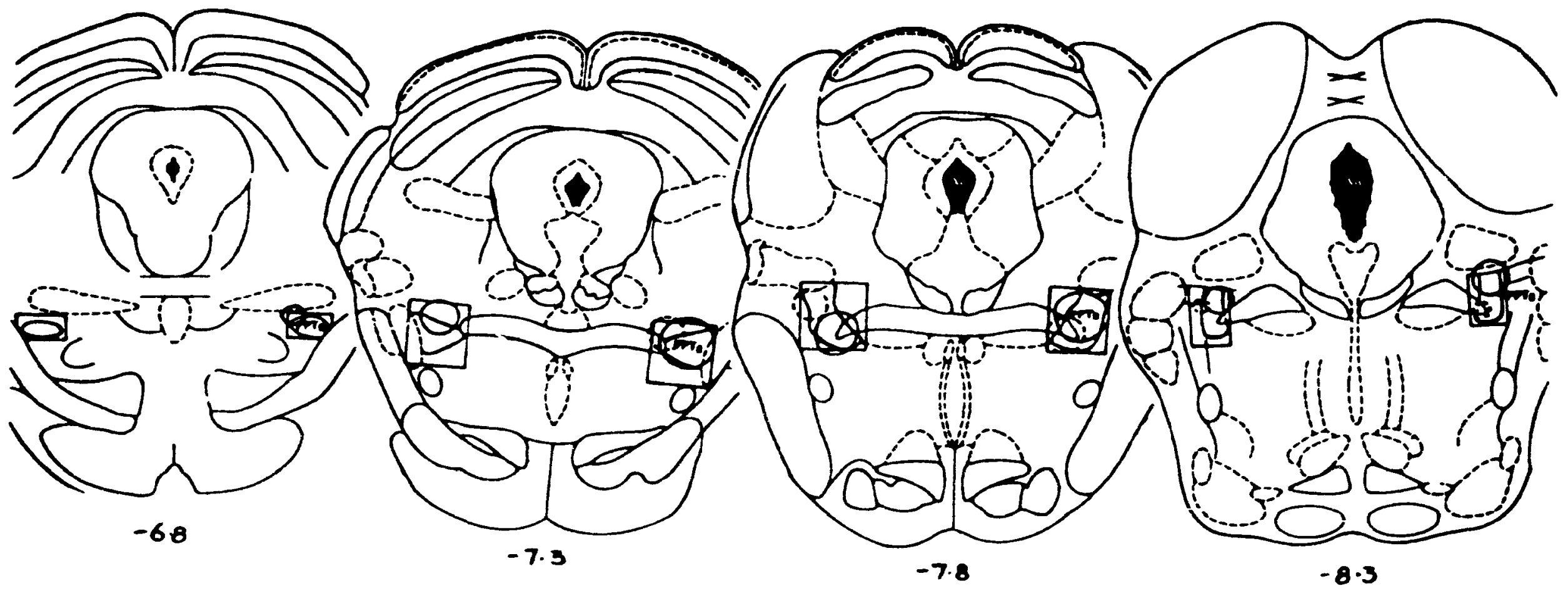

Figure 1. The location and extent of the largest (solid circle) and smallest (dotted circle) PPTg lesions are shown above. ChAT-containing cells were counted within the boundaries outlined by the square box. 
outlined by the square box. Photomicrographs in Figure 2 show the histological appearance of sham (left panel) and NMDA (right panel) lesions, stained with Kluver Barrera (top panel) and NADPH-diaphorase (bottom panel) techniques. Histological examination revealed that 11 animals had extensive lesions of the PPTg and 10 animals had partial lesions. The percentage of cholinergic cells remaining in the PPTg across the two groups ranged from $23 \%$ to $72 \%$

conditioned Place Preference

As presented in Figure 3, sham lesioned animals developed a CPP for the morphine-paired compartment $[t(38)=7.15 ; \mathrm{p}<$ $.01]$, whereas animals with extensive $[t(20)=1.32 ; p=0.2$ NS ] or partial $[t(18)=0.98 ; p=0.34 \mathrm{NS}]$ lesions did not. There was no significant citference between animals with extensive and partial lesions in time spent in each of the large compartments $[F(1,21)=1.93 ; p=0.18$ NS $]$ and no significant correlation between percentage loss of ChAT containing cells and reduction of CPP. Thus, animals with extensive and partial lesions were combined into one group (Lesion): time spent in each of the large compartments was not significantly different for this group $[t(40)=1.66 ; p=0.1$ NS]. Sham lesioned animals spent significantly more time in the morphine-paired versus the saline-paired compartment than animals with PPTg lesions $[F(1,41)=5.4 ; p<.05]$.

The only difference between animals with extensive and partial lesions was that time spent in the drug-paired versus 


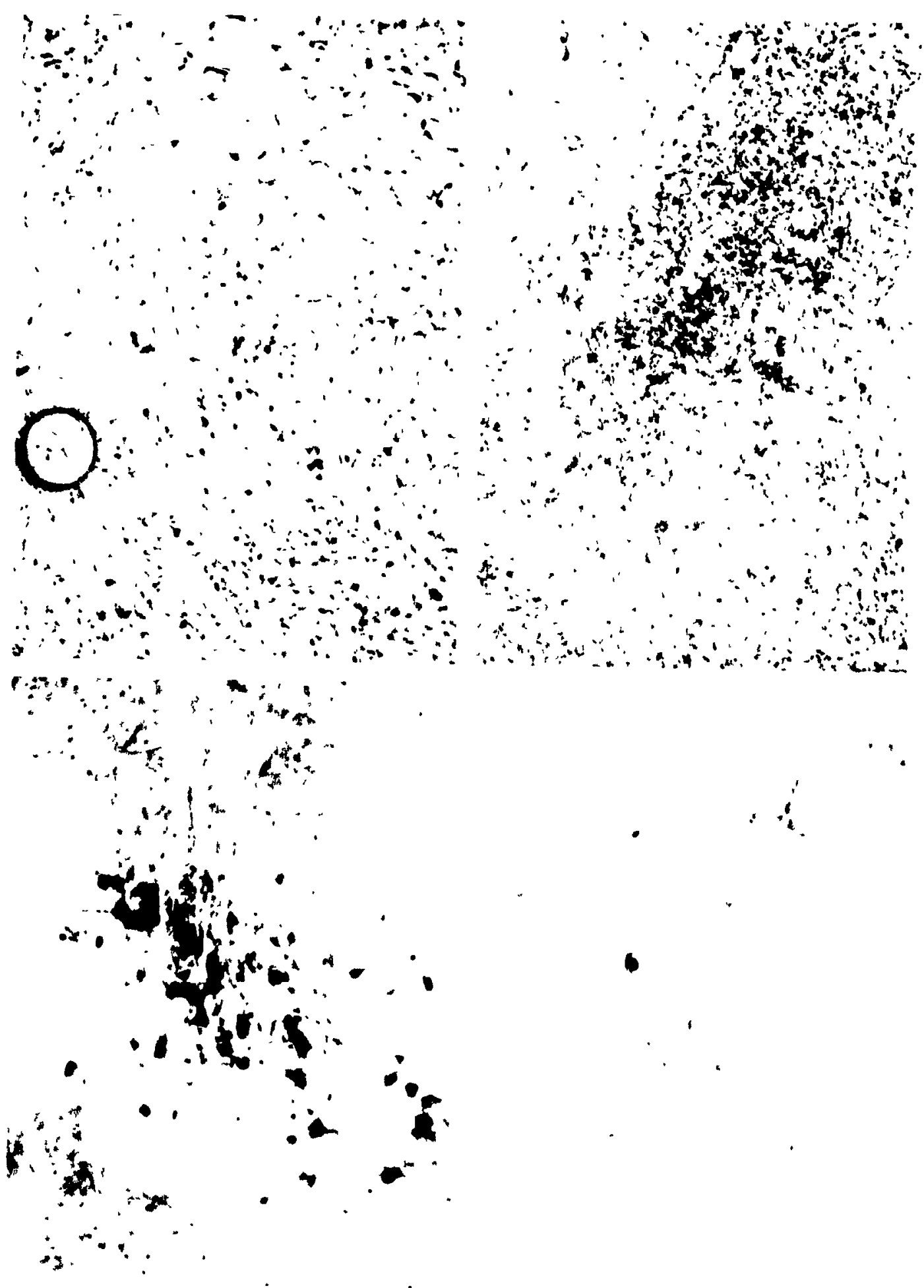

Figure 2. PPTg sham (left panel) and NMDA (right panel) lesions, stained with Kluver Barrera (top panel) and NADPHdiaphorase (bottom panel) techniques. 


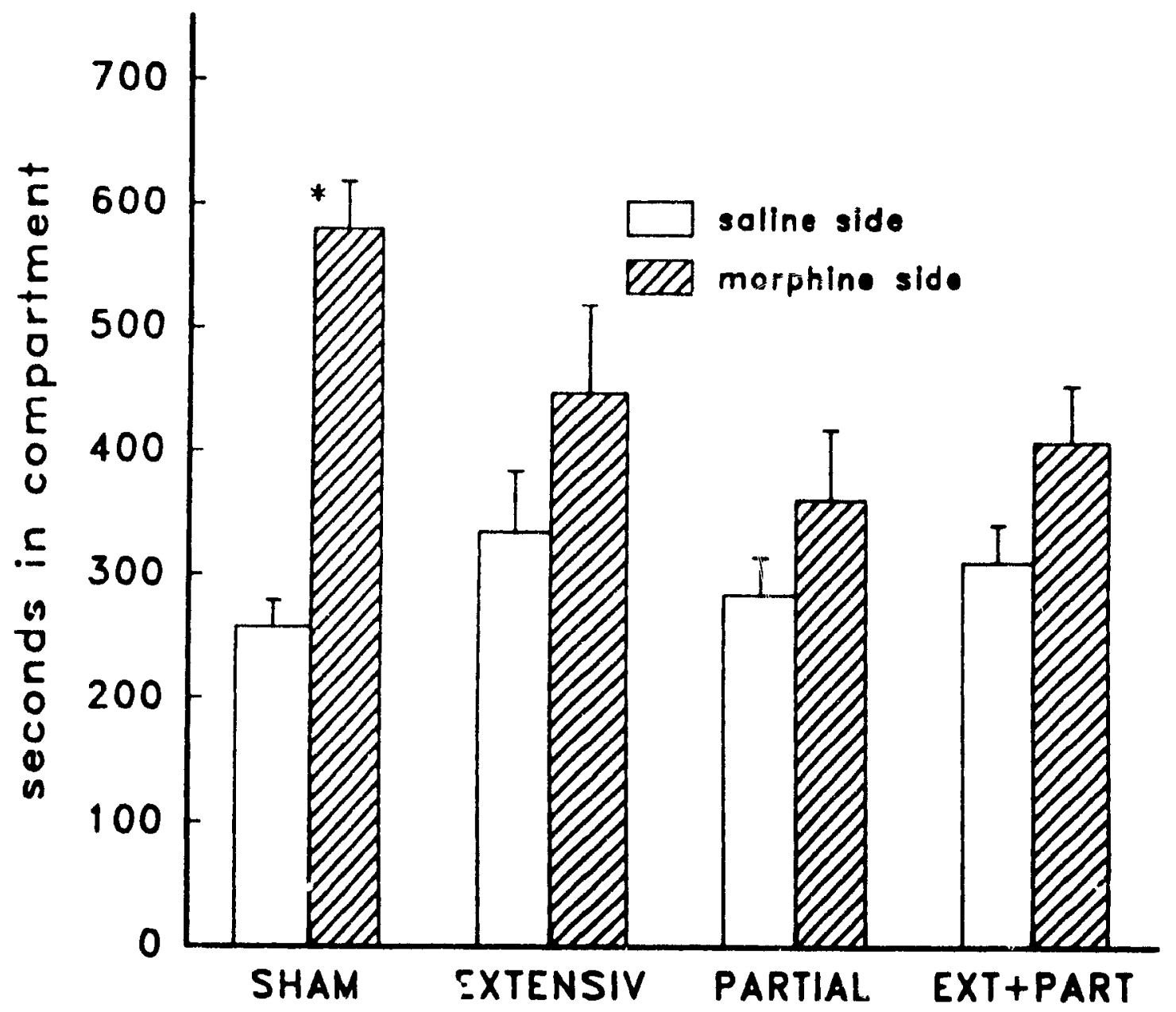

Figure 3. Amount of time spent in saline-paired versus morphine-paired compartments for animals with PPTg sham or NMDA lesions (partial, extensive, or combined groups). 
saline-paired compartments was significantly different between animals with sham and partial lesions $[t(28)=2.85 ; \mathrm{p}<.01]$, but not between animals with sham and extensive lesions [ $t(29)$ $=2.01 ; p=0.06 \mathrm{NS}]$.

During testing, sham lesioned animals spent 49\%, 21\%, and $30 \%$ and PPTg lesioned animals spent $35 \%, 32 \%$, and $33 \%$ of the total time in the conditioned, non-conditioned, and tunnel compartments respectively.

Formalin Testing

As presented in Figure 4, pain scores between PPTg sham and lesioned animals were significantly different $[F(1,41)=$ 12.29; $p<.05]$. There was a significant difference in pain scores between the two groups following morphine administration of $4 \mathrm{mg} / \mathrm{kg}[t(39)=2.47 ; \mathrm{p}<.05]$ and $8 \mathrm{mg} / \mathrm{kg}$ $[t(39)=-2.56 ; p<.05]$. There was no significant difference in pain scores between animals with extensive and partial lesions at morphine doses of either $4 \mathrm{mg} / \mathrm{kg} / t(19)=-.44 ; \mathrm{p}$ $=0.67 \mathrm{NS}]$ or $8 \mathrm{mg} / \mathrm{kg}[t(19)=-.17 ; \mathrm{p}=0.87 \mathrm{NS}]$.

There was no significant correlation between block of reward and block of analgesia for animals with PPTg lesions (extensive, partial, or combined groups).

\section{DISCUSSION}

Results of the present experiment confirm a previous report (Bechara and Van der Kooy, 1989), that excitotoxin lesions of the PPTy block the development of CPP to morphine. They also support Bechara and van der Kooy's proposal that the 


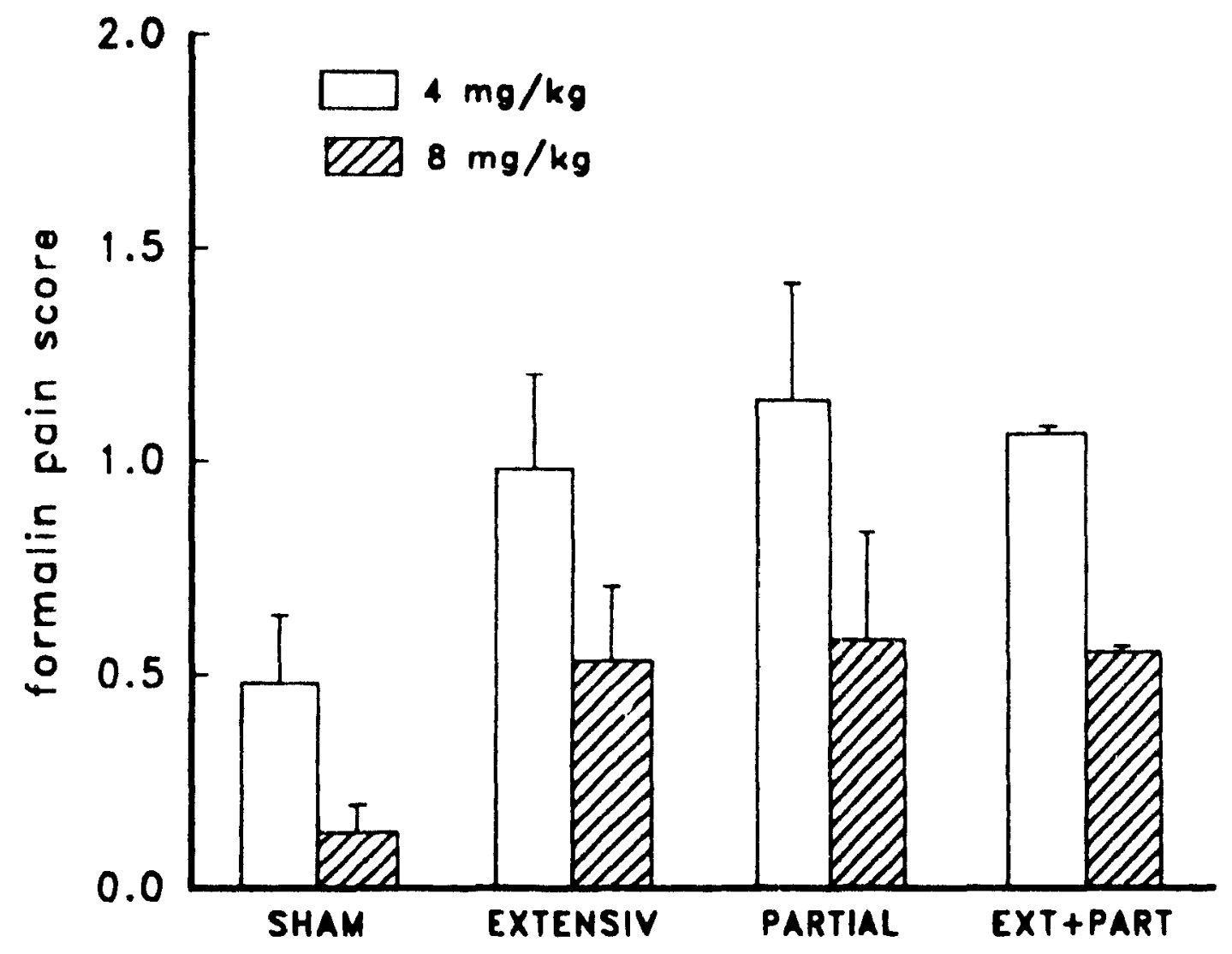

Figure 4. Pain scores in the formalin test for animals with PPTg sham or NMDA lesions (partial, extensive, or combined groups) following morphine adminstration of $4 \mathrm{mg} / \mathrm{kg}$ or $8 \mathrm{mg} / \mathrm{kg}$. 
reduction of reward in PPTg lesioned animals is not correlated with the loss of cholinergic cells in this region. There was no significant correlation between block of reward and loss of ChAT containing cells in the PPTg, and no significant difference in reduction of reward between animals with partial and extensive lesjons. As stated above, except for the cholinergic component, the neurotransmitters in the PPTy are unknown. Thus, the only conclusion concerning the role of neurotransmitters that can be drawn from this study is that morphine reward that involves the PPTg is probably not dependent on cholinergic cells in the region.

The inability to establish a correlation between cholinergic depletion and reward attenuation may provide indirect sipport for Bechara and Van der Kooy's proposal that systems mediating reward in the PPTg can be localized to the ventromedial region. Based on cytoarchitectural features, the PPTg can be divided into two subdivisions: the subnucleus compactus and the subnucleus dissipatus (Olszewski and Baxter, 1954; Newman, 1985). The former region, located at the dorsolateral and caudal portion of PPTg contains large, densely packed neurons; the latter region, located more ventrally and medially at the rostral end of the nucleus, consists of smaller, loosely-scattered neurons (Spann and Grofova, 1989). Subnucleus compactus fibers are predominantiy ascending whereas those from the subnucleus dissipatus make up the majority the spinal cord projections (Spann and Grofova, 
1989). Furthermore, cholinergic cells are concentrated within the PPTg region corresponding to the subnucleus compactus (Spann and Grofova, 1989; Garcia-Rill, 1991).1

Bechara and van der Kooy propose that the PPTg cells mediating morphine reward are ventromedially located, noncholinergic cells, with descending projections. It seems probable, therefore, that their most effective lesions corresponded to the PPTg region associated with the subnucleus dissipatus. In the present study, the Kluver Barrera stained sections did not show sufficient detail to precisely determine the extent of the lesions. ChAT-stained sections showed that lesioned animals in this study had neuronal destruction within the boundaries of the PPTg: extensive lesions with more than $75 \%$ ACh depletion and partial lesions with $50 \%$ to $75 \%$ ACh depletion. Based on the distribution of ChAT-stained cell loss, it can be inferred that the former group had lesions concentrated in the subnucleus compactus region, whereas the latter group had lesions in the subnucleus dissipatus. Given Bechara and van der Kooy's conclusions, this may explain why animals with partial, but not extensive, lesions differed significantly from controls in block of reward.

In addition to attenuating morphine reward, PPTg lesions appeared to reduce the analgesic effects of morphine. However,

1 The two PPTg subdivisions are not entirely distinct in terms of either cytoarchitecture, fiber projections, or neurochemistry; nor are these divisions consistent across species. Therefore, in order to avoid discrepancies, all studies cited, like the present investigation, employed rats as subjects. 


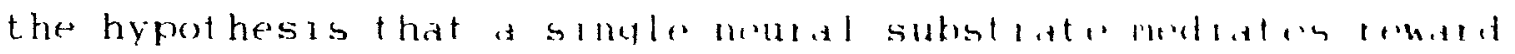

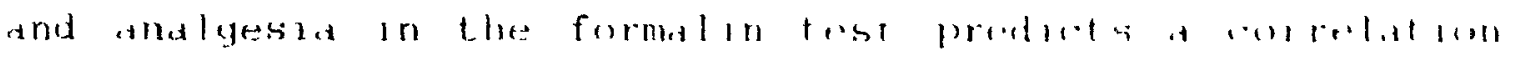

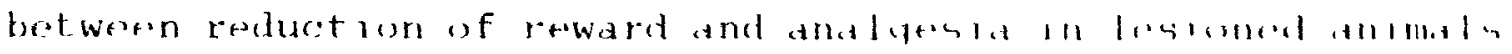

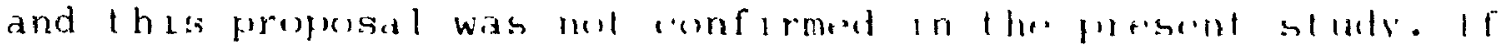

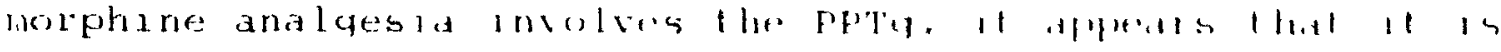

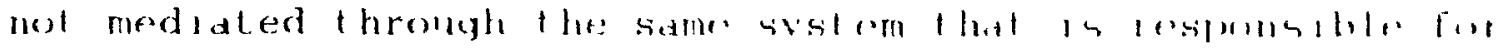
the reinforcing effect of mopphime.

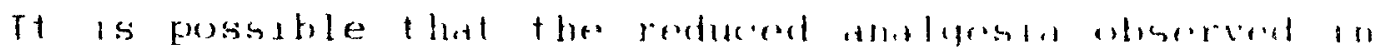

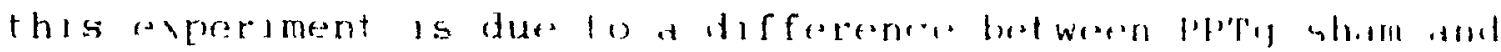

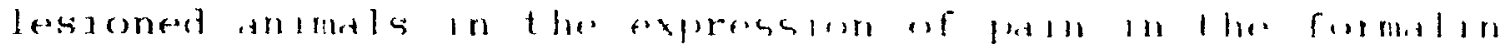

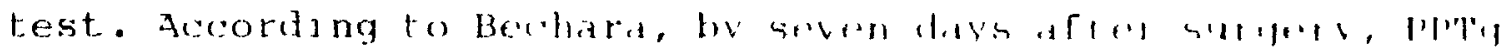

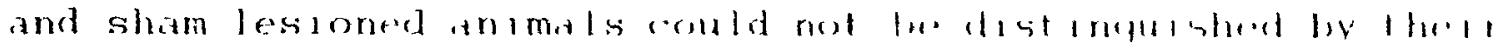

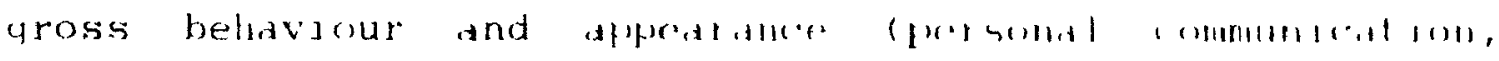

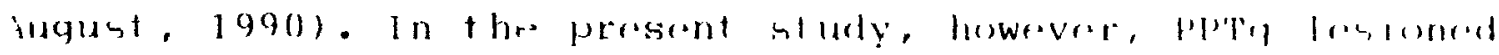

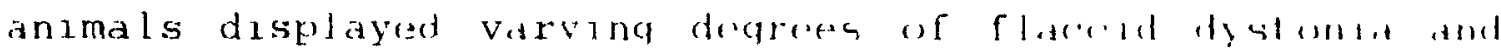

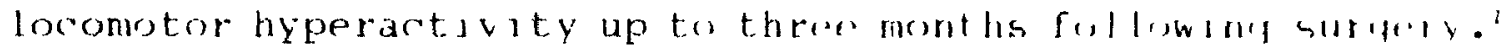

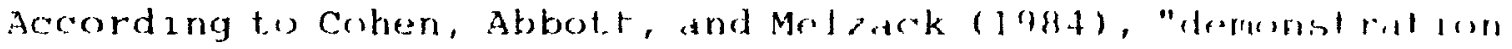

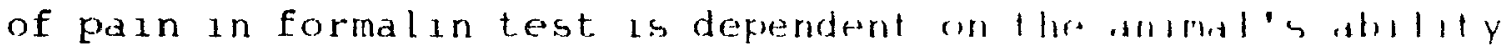

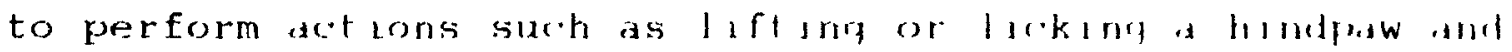

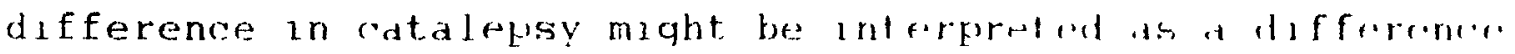

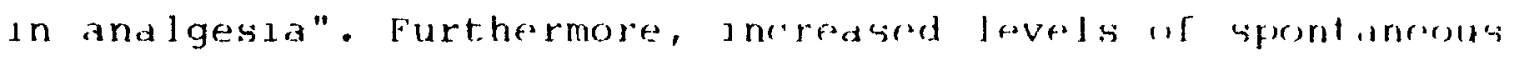

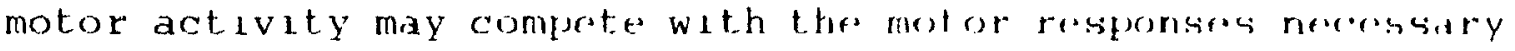
for the demonstrateon of and gesta in the formalin tist (fiel

2 All ansmals were sacrificed after a maximum of 11 . Hor menthis of behavioral testing. There is me reason tor susperet. 1 h.t. differences between sham and lesionod an mals driscrubed abover would disappear after this time period. 
example, paw lifting and licking). Therefore, PPTg lesions may result in general and/or specific motor abnormalities that interfere with the behavioral responses required for expression of pain in the formalin test.

The difference in pain scores between PPTg sham and lesioned anima?s may also be due to a difference in the development of tolerance to the effects of morphine. Formalin testing occured following three injections of morphine (CPP procedure), which may have altereu the response to morphine administration in lesioned animals. These concerns were addressed in Experiment 2 .

\section{Experiment 2}

\section{INTRODUCTION}

In Experiment 1, PPTg lesions eliminated the development of morphine-induced CPP and, following CPP testing, reduced morphine analgesia in the formalin test. The CPP procedure, however, requires a series of morphine injections, which may interact with the effects of lesions to alter pain scores in the formalin test. To eliminate this possible interaction, Experiment 2 assessed the effect of PPTg lesions on formalin pain and morphine analgesia in drug naive animals. Furthermore, PPTg lesioned animals in Experiment 1 often experienced seizures as they were recovering from surgery, which may result in neurotoxin spread and subsequent damage to distal neural sites (Jarrard, 1986). In order to minimize this possibilty, animals were injected post-operatively with 
diazepam. To determine if PPTg lesions produce motor abnormalities, motor abilities of PPTg sham and lesioned animals were examined by evaluating sensorimotor responses, limb use, spontaneous motor activity (SMA), and catalepsy.

\section{MATERIALS AND METHODS}

Subjects, apparatus, surgery, and histology were identical to those described in experiment 1. Different and additjoral procedures used in this experiment are outlined below.

subjects

Nineteen subjects ( 9 lesioned and 10 sham lesioned) were used in the following experiment.

Surgery

To control seizures, all animals were injected interperitonally with diazepam ( $1 \mathrm{mg} / \mathrm{kg})$ immediately following surgery.

Procedures

Formalin Testing

Prior to formalin testing, each subject was injected with saline, $4 \mathrm{mg} / \mathrm{kg}$ morphine, or $8 \mathrm{mg} / \mathrm{kg}$ morphine in a counterbalanced, repeated measures design such that all rats were tested in all conditions. Successive formalin tests occurred at one week intervals.

Neuralogical Tests

One week after the third formalin test, each animals was examined for impairments in sensorimotor responses and limb 
use following the protocol described by Marshall and Teitelbaum (1974). Four aspects of the rat's sensory and motor functionina were examined: (1) orientation to stimuli, (2) limb use, (3) muscular tone, and (4) open field activity.

(1) The ability to orient the head toward olfactory, tactile, or visual stimuli in space and on the body surface was investigated by noting responses to stimuli suddenly introduced on either side of the rat's body. A normal animal turns its head towards the stimulus, often contacts it, and sometimes bites it. In order to minimize locomotion during testing, the animal was placed on a slightly unsteady wire platform. Responses to olfactory stimuli were assessed by moving a cotton swab soaked in ammonia towards the head of the animal such that the stimulus did not enter the visual field or contact the animal's whiskers. Responses to tactile stimuli were assessed by lightly touching the vibrissae on either side of the animal with a cotton swab. Responses to visual stimuii were assessed by holding a $5 \mathrm{~cm}$ X $5 \mathrm{~cm}$ cardboard square approximately $10 \mathrm{~cm}$ away from the rat, and moving it rapidly back and forth across the visual field of each eye. In each of these tests, the animal's response (or lack of response) to the introduction of the stimulus was recorded.

Orientation to visual stimuli was also examined by observing the animal's fore limb placing response. For this test, the rat was held suspended by the tail and lowered slowly from a height of $20 \mathrm{~cm}$ to the table surface. Whether or 
not the animal displayed the normal extension of the forelimbs to meet the table edge was recorded.

(2) Limb use in simple reflexes and movements requiring accurate placement in space was assessed in the following tests: The ability to use the limbs when bracing against a gravitational pull was assessed by placing the rat on a flat wire-rung platform, tilting the platform and observing whether the rat was able to lean against the slant in order to maintain its balance. The use of forelimbs was examined by observing whether an animal could pull itself up into the experimenter's hand when suspended from each forepaw. Accurate limb use was assessed by recording whether an animal could climb $50 \mathrm{~cm}$ through the rungs of a wire cage to a platform without falling. The ability to use limbs to right itself was assessed by placing the animal in a supine position in the palm of the experiment's hand and recording whether it was able to return to an upright position. Limb reflexes were examined by holding the rat around the chest in a vertical position, pinching each limb lightly with forceps, and observing whether the animal withdrew the limb. Proprioceptive lateral hopping was examined by holding the rat in a vertical position and tilting it slightly to one side so that one hind paw touched the table surface and supported much of the rat's weight. The rat was moved laterally across the table surface and it was observed whether the animal was able to successfully adjust to the changing centre of gravity by 
flexing and extending each hind limb. Proprioceptive placing of the hind limbs was measured by holding the rat in a vertical position, positioning one hind paw underneath the table surface, moving the rat upwards, and observing whether the animal flexed the limb and placed it on the table surface.

(3) Muscular tone was assessed by holding the rat in a vertical position around the chest and passively flexing and extending each limb. Resistance was rated on a four point scale: no resistance or $\mathrm{flaccid}=1 ; \mathrm{mild}$ resistance or little opposition to flexion $=2$; medium resistance or some opposition to flexion $=3$; high resistance or difficult to flex $1 \mathrm{imb}=4$. Resistance scores for each limb were added so that the possible range of muscle tone score for each animal was 0 to 16 .

(4) In addition, each animal was placed for 15 minutes on a $75 \times 60 \mathrm{~cm}$ table surface. The pattern of movement was traced on a paper to determine the total activity as well as how frequently the animal turned in each direction. During this period. the animal was observed for abnormalities in posture, grooming, or other movements.

Spontaneous Motor Activity

SMA was measured during the second habituation session before the first formalin test. The plexiglass floor of the formalin test cubicle was divided into four quadrants and the number of times that the rat crossed from one quadrant to another was recorded. All four paws had to be in a new 


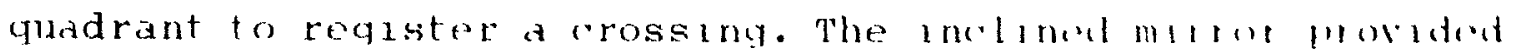

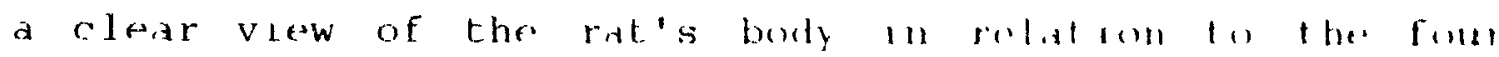

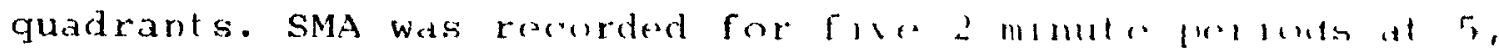

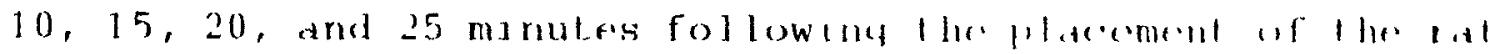

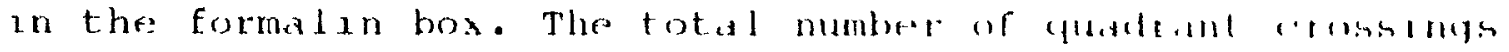

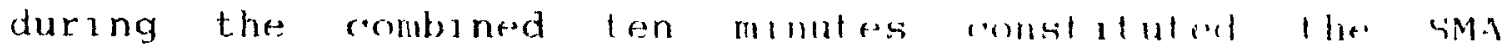
measurement for each rat. One work aftel llw last rommlin test, SMA Was measured for eabh andmal follawini a subcutaneous in pertaon of mosphams (10 ma'ka).

Calalepsy

Followime adoh SMA list, the ret was removert from the. test box and tested for catalepsy us lua l he al andud bat lest

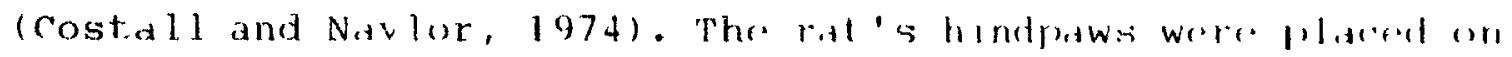

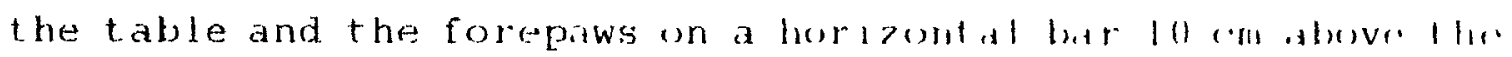
table. The tame for the rat lo place bolh forelitwe on 1 ha. table was recorded. A raxumum of 60 becondis was rese orded if

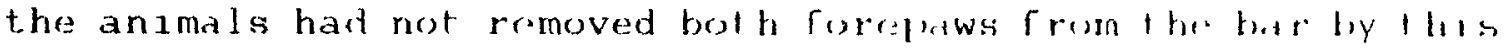
t 1 me.

Statistacal Analysis

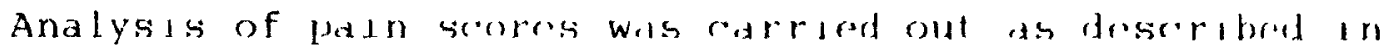
expersment 1. SMA and catalepsy sroress were andlyerd using 2way independent merasures ANOVA with group as one fartor end drug condition as the other factor (rropeated mosesuresi). Falrwise comparisons were performed using Tukey' 's fireterelded 'J test. Dose response curves were obt a lned by plot 1 ma man smi or catalepsy score against dose. 


\section{RESULTS}

\section{Histology}

The location and extent of the largest (solid circle) and smallest (dotted circle) PPTg lesions are shown in Figure 5 on the following page. ChAT containing cells were counted within the boundaries outlined by the square box. Based on the criterion employed in experiment 1, 4 animals had extensive lesions and 5 animals had partial lesions of the PPTg. The percentage of ChAT containing cells remaining ranged from $29 \%$ to $59 \%$. There was no significant difference between animals witn extensive and partial lesions in any test, and no significant correlation between size of lesion and any behavioral measure. Therefore, animals with extensive and partial lesions were combined into a single group (Lesion). Formalin Testing

As presented in Figure 6, PPTg lesions had no significant effect on pain scores in the formalin test $F(1,19)=0.016$; $p=0.97 \mathrm{NS}]$. There was no significant difference between pain scores of PPTg sham and lesioned animals in any condition: saline $[t(18)=1.16 ; \mathrm{p}=0.26 \mathrm{NS}], 4 \mathrm{mg} / \mathrm{kg}$ morphine $[t(18)=$ $0.04 ; \mathrm{p}=0.97 \mathrm{NS}]$, and $8 \mathrm{mg} / \mathrm{kg}$ morphine $[t(18)=-1.41 ; \mathrm{p}=$ 0.18 NS ].

Neurological Tests

PPTg sham and lesioned animals did not differ in orientation responses to either ol factory, visual, or tactile stimuli; both groups displaying responses typical of normal 


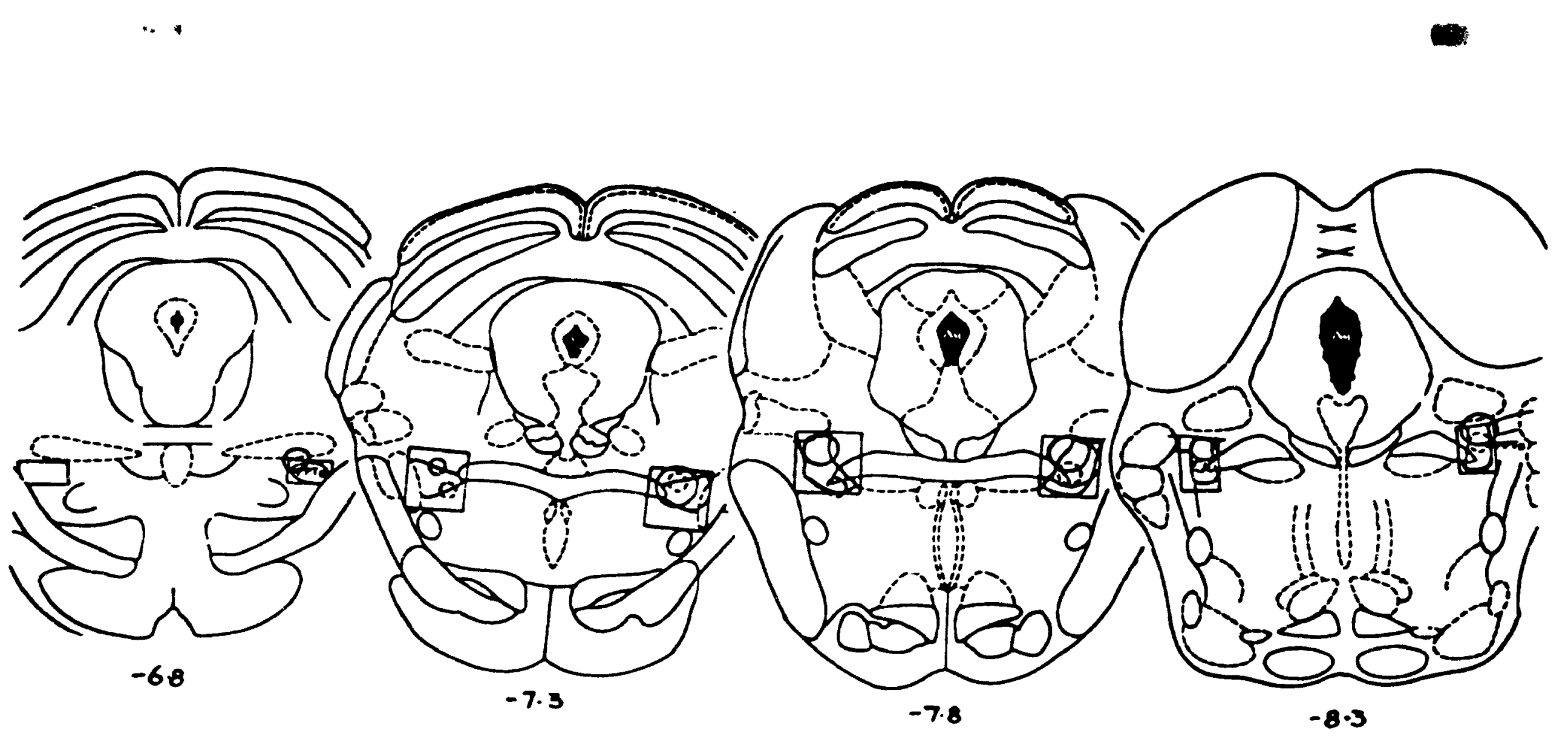

Figure 5. The location and extent of the largest (solid circle) and smallest (dotted circle) PPTg lesions are shown above. ChAT-containing cells were counted within the boundaries outlined by the square box. 


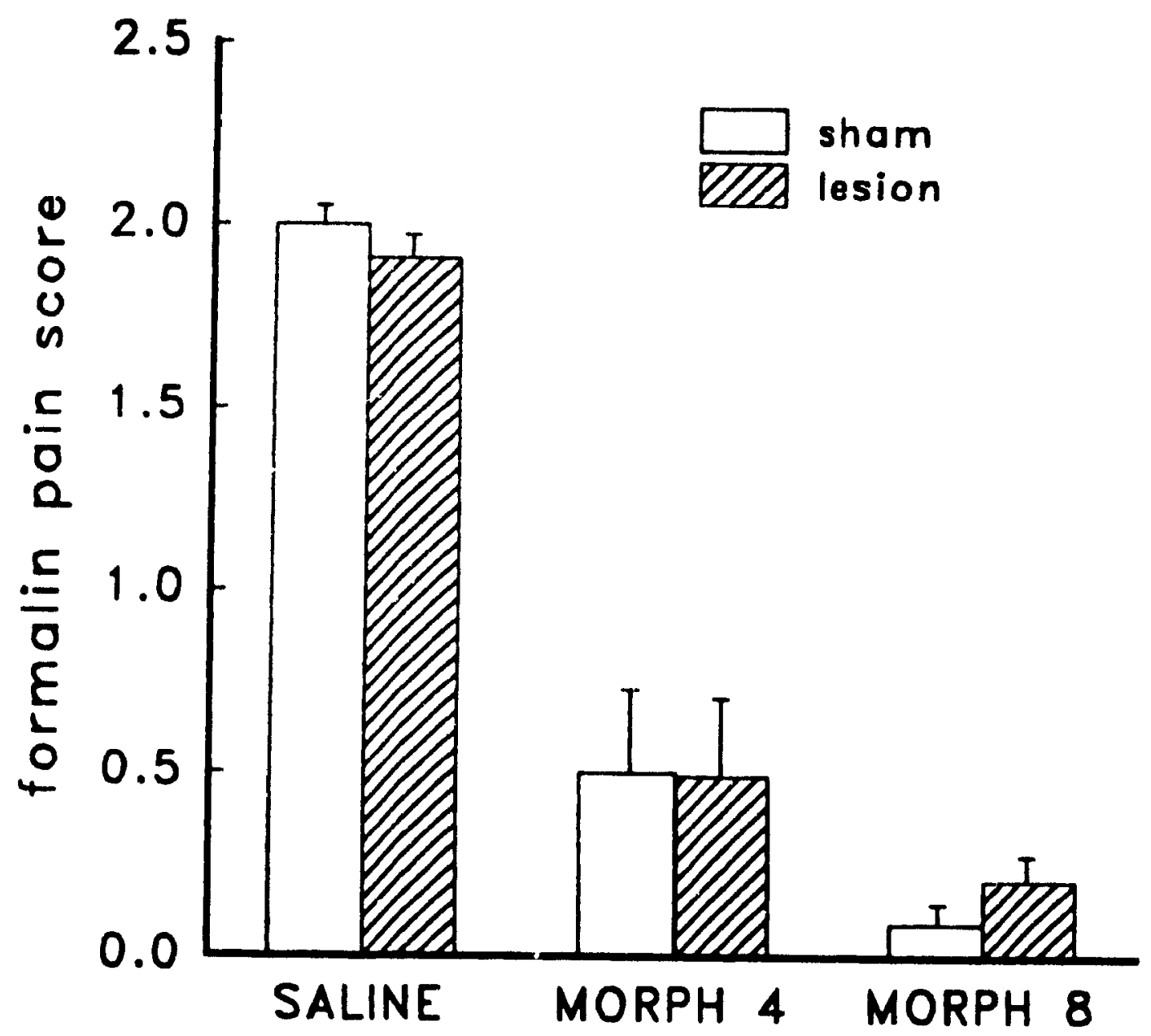

Figure 6. Pain scores in the formalin test for PPTg sham and lesioned animals following injections of saline, $4 \mathrm{mg} / \mathrm{kg}$ morphine, or $8 \mathrm{mg} / \mathrm{kg}$ morphine. 
rats. However, PPTg lesioned animals did not always extend their fore limbs as they were lowered towards the table surface. In Figure 7 a PPig sham and lesioned animal are shown suspended approximately $20 \mathrm{~cm}$ above a table surface. The sham lesioned animal displays the normal response of forelimb extension whereas the lesioned animal does not. PPTg lesioned animals also exhibited deficits in limb use: 7 of the 9 lesioned animals, were unable to pull themselves up when suspended by the forepaws and 6 lesioned animals failed to accurately climb through the rungs of a wire cage. Furthermore, muscle resistance of PPTg lesioned animals (mean score $=12.2$ ) was significantly different than shams (mean score $=9.2)[t(17)=-2.49 p<.05)$. Open field activity of PPTg sham and lesioned animals did not differ.

spontaneous Motor Activity

To eliminate non-homogeneity of variance and a correlation between means and variances, a square root transformation was applied to the SMA scores. As shown in the top panel of Figure 8, morphine inhibited SMA in sham lesioned animals whereas SMA was not significantly different in morphine and drug free trials for PPTg lesioned animals. [Interaction $\mathrm{F}(1,19)=8.23 ; \mathrm{p}<.05]$.

Catalepsy

Catalepsy scores for PPTg sham and lesioned animals in morphine and drug free trials are shown in the bottom panel of Figure 8. Morphine administration significantly increased 

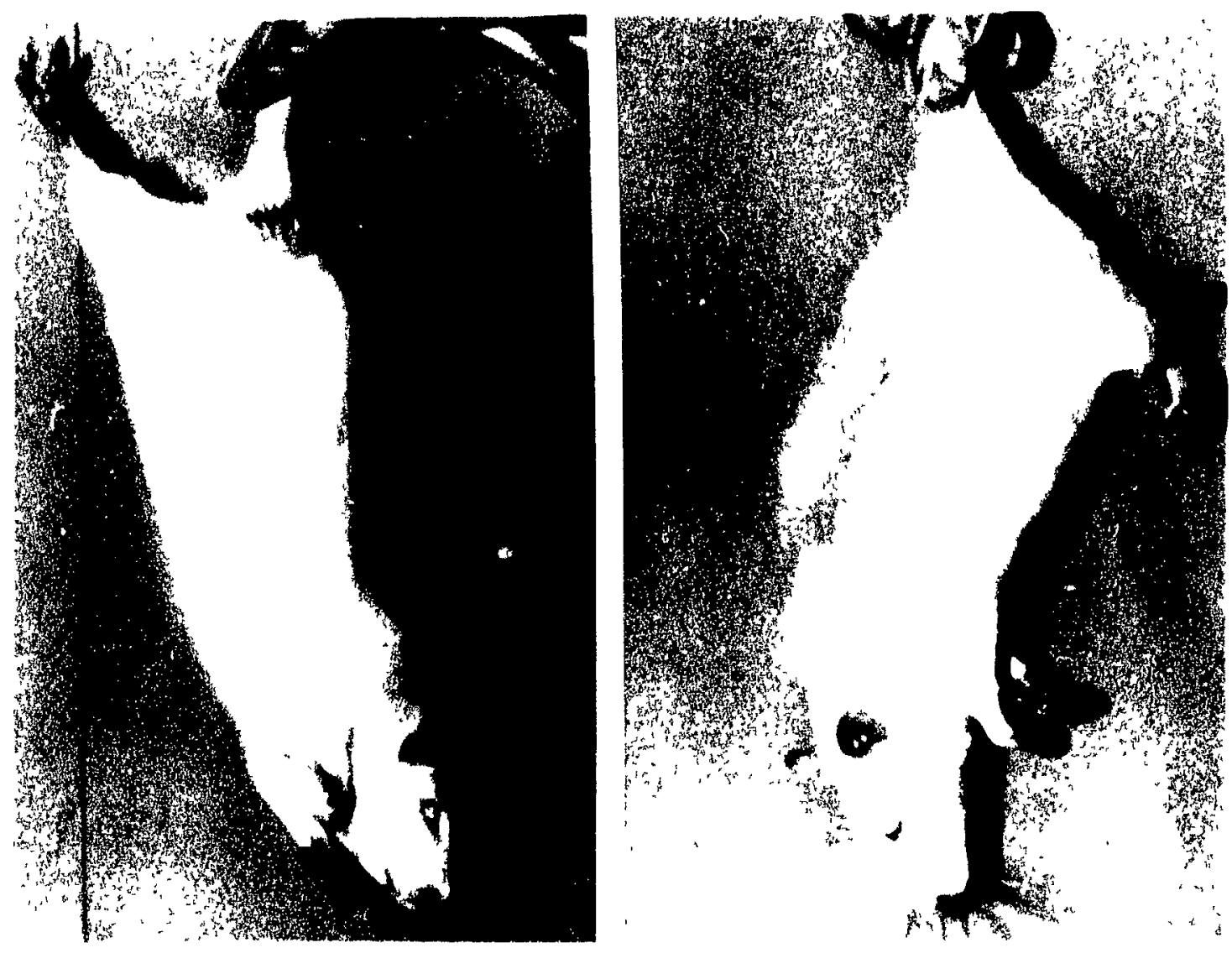

Figure 7. A PPTg sham (left panel) and lesioned animal (right panel) are shown suspended approximately $20 \mathrm{~cm}$ above a table surface. 


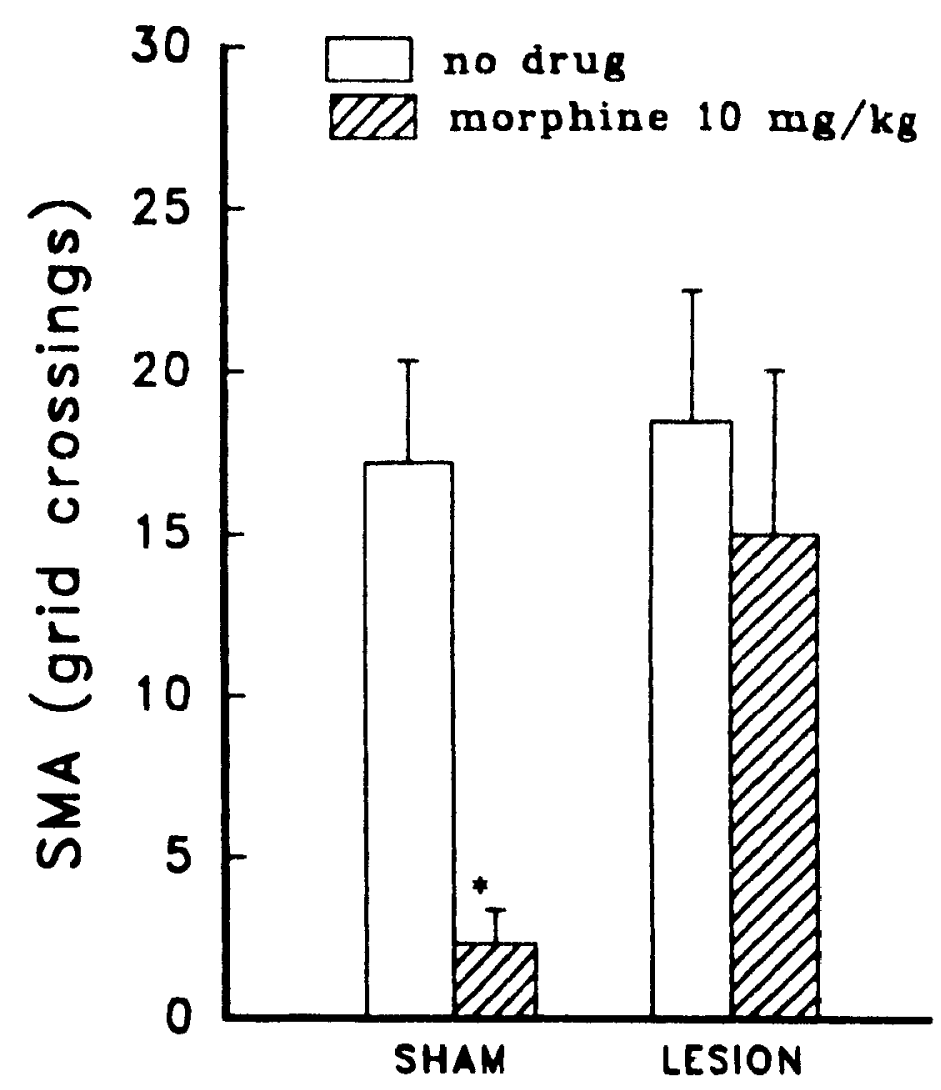

47

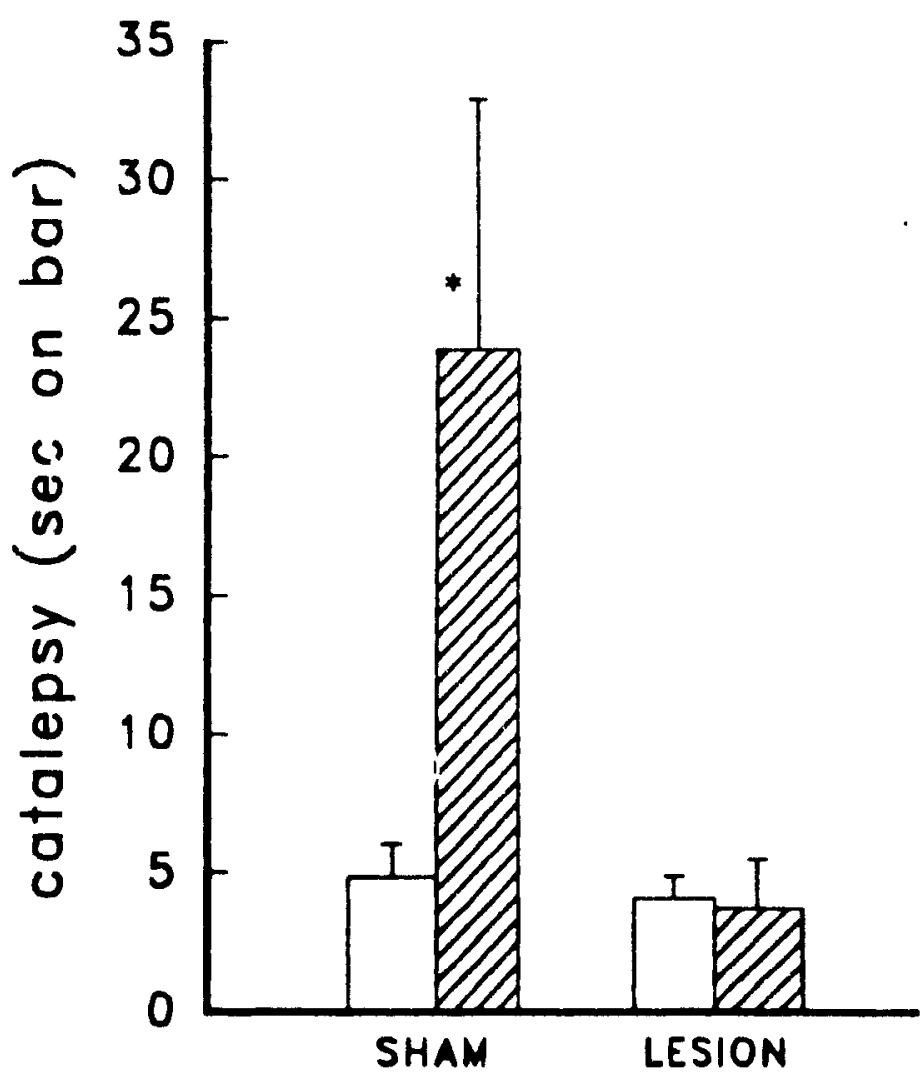

Figure 8. SMA (top panel) and catalepsy (bottom panel) scores for PPTg sham and lesioned animals in morphine and drug-free trials. 
catalepsy scores for sham lesioned, but not PPTg lesioned animals [Interaction $F(1,19)=4.59 ; \mathrm{p}<.05$ ]

\section{DISCUSGION}

In Experiment 2, drug naive rats with lesions of the PPTg were not impaired in their ability to express pain in the formalin test. These results are consistent with the observation (Matthies and Franklin, 1990) that responses to formalin injection are normal in animals with transcctions at the level of, or caudal to, the PPTg. Graybiel and Ragsdale (1978) suggest that the PPTg may be involved in centre of gravity control and other postural functions during locomotion; nevertheless, it appears that destruction of the region does not interfere with the complex movements and postural adjustments necessary for expression of pain in the formalin test.

Despite their normal pain responses, animals with PPTg lesions did exhibit abnormalities in limb use and muscle tone. These observations are consistent with previous investigations. For example, Buscher et al. (1989) report that animals with NMDA lesions of the PPTg display increased muscle tone and are impaired in righting reflexes, and Garcia-Rill et al. (1990) found that neurotoxin injections into the PPTg create a dose dependent increase in locomotion as well as an increase in muscle tone. Given that the PPTg is reciprocally connected with various extrapyramidal motor structures, it is 
likely that lesions in this area produce disturbances in extrapyramidal motor system functioning.

Contrary to the findings in Experiment 1, results of the present study indicate that the PPT does not mediate the analgesic effect of morphine in the formalin test. It is possible that animals in Experiment 1 may have suffered greater motor deficits than those in Experiment 2. Although PPTg coordinates and administration of NMDA were identical in the two experiments, animals in Experiment 2, unlike those in Experiment 1, received injections of diazepam following surgery. As a result, only 1 of 9 lesioned animals in the second experiment, compared to 18 of 21 in the first experiment, experienced seizures during recovery. Ben-Ari et al. (1980) report that seizures resulting from neurotoxin injections produce brain damage at local and distal sites, both effects being reduced by diazepam. Although PPTg lesions in the two groups did not differ significantly, it is possible that the seizures experienced by lesioned animals in Experiment 1 caused neural damage in regions remote from the injection site, and that this caused animals with PPTg lesions to be impaired in their ability to express pain in the formalin test. This hypothesis can not be confirmed, however, because motor abilities of animals employed in Experiment 1 were not examined in detail. Moreover, pain scores in the absence of morphine were not assessed in these animals. 
It is important to note that animals treated post surgically with diazepam in Experiment 2 were not subjected to CPP testing. Similarly, lesioned animals in Bechara and van der Kooy's (1989) study dia not receive anti-convulsants, making it likely that their animals also experienced seizures and, consequently, damage at unspecified sites distal from the PPTg. Although it seems unlikely, it is possible that neurotoxin lesions in both Bechara and van der Kooy's study and Experiment 1 caused neural damage in regions beyond the PPTg that affected morphine reinforcement in these experiments. In order to assess this possibility, it will be necessary to test the effect of PPTg lesions on the development of a morphine-induced CPP in animals treated with diazepam to relieve seizures.

In addition to neurological tests, differences in motor functioning between PPTg sham and lesioned animals were assessed in two measurements: SMA and catalepsy. Results support previous reports (Dellu et al., 1991; Bechara, personal communication, July 1991) that PPTg lesions do not affect SMA or catalepsy in drug free trials. The present study revealed, however, that lesions of this region block morphine's effects on the two behaviours; that is, compared to sham lesioned animals, animals with PPTg lesions did not exhibit a decrease in SMA or an increase in catalepsy following morphine administration. Similarly, Matthies and Franklin (1990) observed that animals with transections of the 
rostral pons generally exhibit the normal inhibition of SMA and increased catalepsy following morphine administration, whereas animals with transections caudal to the PPTg do not show these changes. Both findings suggest that the PPTg in involved in mediating the effect of morphine on SMA and catalepsy.

In contrast to results from the present study, Bechara and van der Kooy (1991b) report that PPTg lesions do not alter the effects of morphine on SMA and catalepsy. This discrepancy is probably due to a difference in the location of lesions between the two studies. According to Garcia-Rill (1986), the anteriorally located subnucleus pars compactus region of the PPTg (where the cholinergic cells are concentrated) is responsible for its motor effects. Animals in the present study probably had neural destruction in this region because lesions depleted between $41 \%$ and $71 \%$ of ACh cells. Bechara and van der Kooy's lesions may have been more selective, sparing the majority of cells in this region and, therefore, not affecting PPTg mediated motor responses. In support of this interpretation, Bechara and van der Kooy did not observed any gross behavioral differences between PPTg sham and lesioned animals whereas sham and lesioned animals in the present study appeared different under superficial examination. Although the subnucleus compactus region may be associated with PPTg mediated motor effects, there was no significant correlation between ACh loss and reduction of morphine effect. This 
suggests that the cholinergic cells in this region may not be responsible for the inhibition of SMA and increase in catalepsy following morphine administration.

Another possible source of discrepancy between results from the present study and those of Bechara and van der Kooy is a difference in testing procedures. Bechara and van der Kooy assessed SMA over a two minute period, two minutes after drug administration; testing in the present study began thirty minutes following the injection and continued for thirty minutes (during which time SMA was assessed in five, two minute bins). Similarly, catalepsy was measured fifteen minutes after morphine adminstration in Bechara and van der Kooy's study, and sixty minutes following adminstration in the present study. Given that the maximal effect of morphine peaks between 45 and 60 minutes following subcutaneous injections, measurements of SMA and catalepsy in the present experiment may be more accurate reflections of the effect of PPTg lesions on SMA and catalepsy following morphine administration.

By their own reports, low levels of SMA following morphine administration may make the paradigm employed by Bechara and van der Kooy insensitive to detecting differences between PPTg sham and lesioned animals. Rather than measuring SMA over a long period (as in the present study), the authors address this concern by examining the effect of PPTg lesions on morphine induced catalepsy. Since an animal that is cataleptic is likely to exhibit low levels of SMA, it seems 
reasonable to assume a relationship between the twu measurements. In the present study, however, there no significant correlation between SMA and catalepsy for RPTg sham and lesionec animals in either morphine or drug free trials, indicating that, although the two effects may be related, they are not alternative measurements of a single phenomenon.

Finally, Hand and Franklin (1985) demonstrated that the mechanisms responsible for morphine catalepsy are dissociable from those involved in the development of tolerance to the effect. Lesioned animals in the Bechara and van der Kooy's study differed from animals in Experiment 2 in terms of previous drug experience: compared to the present study, animals tested for SMA in Bechara and van der Kooy's study had more morphine experience whereas those tested for catalepsy had less. Furthermore, in the present study differences between PPTg sham and lesioned animals in response to morphine adminstration were observed following the first morphine injection. Therefore, although tolerance to the effects of morphine may have affected measurements in both studies, it seems unlikely that differences in tolerance explain the contradictory results concerning the role of the PPTg in mediating SMA and catalepsy following morphine administration. 


\section{GENERAL DISCUSSION}

The purpose of the present study was to examine the relationship between neural substrates mediating reinforcement and analgesia. It has been proposed that analgesia in the formalin test is mediated by reward systems known to be involved in the reinforcing effects of drugs and ICSS, particularly DA projections from the V'rA to the NA (Franklin, 1989; Lin et al., 1989; Morgan and Franklin, 1990). Matthies and Franklin (1990) demonstrated that the organization of motor responses necessary for the expression of pain in the formalin test remains intact in animals with transections of the rostral metencephalon; thus, in order to produce analgesia, forebrain systems mediating reinforcement must be capable of modulating behavioural responses to pain at the level of the brainstem. As reviewed in the Introduction (page 16), the PPTg receives projections from limbic structures associated with both reinforcement and projects to motor system structures. Anatomical connections suggest, therefore, that this brainstem nucleus may have a role in reinforcement and analgesia. To test this hypothesis, the present study examined the effect of PPTg lesions on the reinforcing and analgesic effects of morphine, and quantitatively assessed the role of cholinergic cells in the two effects.

In Experiment 1, PPTg lesions blocked the development of a CPP to morphine, thereby confirming that the region is involved in the reinforcing effect of morphine. Previous 
evidence suggests that the reinforcing effect of amphetamine is also mediated through this region (Bechara and van der Kooy, 1989). Moreover, ICSS in the vicinity of the PPTg is reinforcing (Crow, 1972; Huston et al., 1984), and radio frequency or neurotoxin lesions of the PPTg decrease the reinforcing value of lateral hypothalamic ICSS (Buscher et al., 1989). Thus, Experiment 1 supports the hypothesis (Koob and Bloom, 1988; Mogenson et al., 1987) that the PPTg may be a critical site in neural systems mediating reinforcement.

Because the PPTg is a heterogenous nucleus (Garcia-Ri1l, 1991), containing subpopulations of neurons with distinct ascending or descending fibers and little collateralization (Goldsmith and van der Kooy, 1989), it seems probable that separate functions may be associated with various PPTg regions (Spann and Grofova, 1989: Goldsmjth and van der Kooy, 1989). Bechara and van der Kooy (1989) propose that ACh cells in this region are not involved in drug reinforcement: Results of Experiment 1 confirm this suggestion by demonstrating that there is no relationship between loss of ChAT containing cells in the PPTg and block of morphine reward.

Koob and Bloom (1988) propose that the neural circuit through which the reinforcing effect of drugs is mediated includes DA projections from the VTA to the NA, NA projections to the VP, and VP projections to the PPTg. Bechara and van der Kooy (1989) agree that the reinforcement circuit descends from Iorebrain limbic sites through the PPTg, and further propose 
that PPTg efferents mediating drug reinforcement descend to the ventromedial medulla and spinal cord. In contrast, Rompré and Trudeau (1991) report that the electrophysiological characteristics of PPTg neurons driven by ICSS in the lateral hypothalamus, fall within the range of estimates for neurons responsible for mediating the behaviour. They suggest, therefore, that PPTg neurons involved in reinforcement ascend to, rather than descend from, limbic sites.

Results from the present study do not provide any information into the direction of the reinforcement circuit beyond the PPTg: Although it was shown that cholinergic components of the PPTg are not involved in the reinforcing effect of morphine, there are both ascending and descending non-cholinergic fibers originating in the PPTg (Kang and Kitai, 1990). Nevertheless, cell bodies with ascending and descending efferents appear to be anatomically segregated within the PPTg (Goldsmith and van der Kooy, 1988), and it may be possible to selectively lesion PPTg neurons with ascending or descending connections. In this way, subsequent examinations of the effects of anatomically distinct lesions on reinforcement may provide insight into whether the drug reinforcement circuit ascends and/or descends beyond the PPTg. Implicit in examinations of reward mechanisms, is the assumption that neural systems activated by drugs and ICSS are the same as those activated by natural rewards. This hypothesis is supported by evidence that the reinforcing 
properties of natural reinforcers, like those of drugs and ICSS, appear to be dependent on DA projections from the VTA to the NA (Wise, 1988). Recently, Bechara and van der Kooy (1991c) demonstrated that substrates mediating the reinforcing effects of morphine and of food in non-deprived animals are isomorphic at the level of the PPTg, suggesting that this nucleus may also be part of a neural circuit through which the reinforcing properties of natural rewards are mediated.

Although PPTg lesions block the reinforcing effect of morphine, Experiment 2 showed that they do not affect morphine analgesia in the formalin test. Thus, the hypothesis that reinforcement and analgesia in the formalin test are mediated through a single neural substrate was $n$ verified. These results, however, do not contradict the proposal that analgesia reflects a change in the affective component of pain (Beecher, 1959; Jaffe and Martin, 1975; Franklin, 1989). Rather, the evidence presented above indicates that, at the level of the PPTg, systems mediating reinforcement are dissociable from those involved in the inhibition of reactions to aversive stimulation. It is still possible that brainstem structures and systems which mediate the expression of pain in the formalin test receive input from systems associated with reinforcement such that the perception of pain is altered, responses are inhibited, and analgesia in produced.

stimuli that induce positive affect and those that produce relief from distress are both reinforcing, but may be 
mediated through separate neural systems (Wise, 1988); there is evidence that these systems are separate at the level of the PPTg. For example, PPTg lesions block the reinforcing effect of morphine in drug naive but not dependent animals, and block the reinforcing effect of food in sated but not food deprived animals (Bechara and van der Kooy, 1991c). Moreover, if the aversive effects of morphine withdrawal are alleviated, morphine reinforcement is expressed in dependent animals, and this effect is blocked by PPTy lesions (Bechara and van der Kooy, 1991a). One interpretation of these findings is that the PPTg mediates the reinforcing effect associated with positive affect, but not the reinforcing effect produced by relief from distress. Inhibition of formalin-induced pain by morphine may be similar to alleviation of hunger by food, or of morphine withdrawal by morphine, in that the animal's suffering is relieved by the treatment. The present finding that PPTg lesions blocked the reinforcing, but not the analgesic, effect of morphine, would be consistent with the interpretation that the region is involved in mediating reinforcement of rewarding stimuli, but not reinforcement due to termination of distress (Bechara et al., 1991).

Results from Experiment 2 also demonstrate that neural systems mediating morphine analgesia can be dissociated from those involved in morphine's effects on catalepsy and SMA. In this study, animals with PPTg lesions displayed normal analgesic responses to morphine; the same animals, however, 
did not show the characteristic decrease in SMA and increase in catalepsy following morphine administration. In addition, the reduced motor effects of morphine were not significantly correlated with the reduction of ChAT containing cells in the PPTg. Thus, it appears that the morphine-induced catalepsy and decrease in SMA are mediated through a system that involves non-cholinergic portions of the PPTg. Furthermore, systems mediating morphine's effects on catalepsy and SMA are independent of systems mediating morphine analgesia because PPTg lesions blocked morphine-induced catalepsy and inhibition of SMA, but did not affect morphine analgesia.

It is perhaps not surprising that neural systems mediating the reinforcing effect of rewarding stimuli and of pain relief are dissociable at the level of structures involved in motor mechanisms because motor responses to continuous painful stimuli would be expected to be different from those associated with rewarding stimuli. For example, pain is likely to be manifested by protection of the injured limb whereas reinforcement related to natural rewards is generally associated with forward locomotion (Glickman and Schiff, 1967; wise and Bozarth, 1987). Furthermore, the two behaviours may compete with each other since pain and/or injury tend to inhibit forward locomotion. It is likely, therefore, that distinct brainstem sites are involved in organizing motor responses for the expressior of pain and forward locomotion. If this is true, systems mediating 
reinforcement and analgesia may overlap at forebrain sites, but send efferents to distinct brain stem regions which organize motor responses.

Given that the PPTg is involved in the reinforcing effect of rewarding stimuli, but not of analgesia, the region should also be associated with the initiation of forward locomotion, but not the expression of pain. In support of this proposal, findings in Experiment 2 confirm that the PPTg is not involved in the behavioural responses to formalin-induced pain, and previous studies indicate that the region is involved in the induction of forward locomotion. For example, in the rat, the MLR, which is involved in initiating locomotion, includes both the anterior and posterior portions of the PPTg $^{3}$ (Skinner and Garcia-Rill, 1984). Further, stimulation of the subnucleus pars compacta region of the PPTg elicits controlled rhythmic locomotion (Garcia-Rill et al., 1987), such that increasing stimulation drives the frequency of stepping from a walk, to a trot, and ultimately to a gallop. Locomotion can also be induced by injections of GABA antagonists (Garcia-Ri11, 1985), Substance P (Garcia-Rill, 1986), or NMDA (Garcia-Rill et al., 1990) into the PPTg. In addition, the rhythmic pattern of activity in the PPTg, associated with spontaneous locomotion persists even if the limbs are restrained (Garcia-Rill et al., 1983), providing further evidence that the region is important

' The MLR constitutes different anatomical areas in different species; its function may also vary between species. 
in the initiation of locomotion. PPTg locomotion is likely mediated through reticulospinal projections from this region to spinal cord generators involved in control of rhythmic limb movements (Garcia-Rill, 1986; Mogenson et al., 1985). Furthermore, ascending projections from the PPTg may modulate locomotion by relaying basal ganglia information back to the thalamus and cortex (Mogenson and Wu, 1986). Evidence from Experiment 2 that PPTg lesions do not block SMA in drug free trials is not inconsistent with the suggestion that the region is involved in generating forward locomotion because the PPTg does not constitute the entire MLR (Garcia-Rill et al . 1986) and a number of pathways are capable of modulating locomotion (Garcia-Rill et al., 1987).

As outlined in the Introduction, neural systems mediating antinociception in reflex withdrawal tests and analgesia in the formalin test are at least partly independent (Abbott et al., 1982; Abbott and Melzack, 1982; Abbott and Mel zack, 1983; Ryan et al., 1985; Morgan and Franklin, 1990); results from the present study provide further indirect support for this hypothesis. PPTg lesions in the present study did not affect morphine analgesia in the formalin test. On the other hand, stimulation of the PPTg increases tail flick latencies from noxious heat (Fitzgerald and Proudfit, 1989; Haws et al., 1989), the effect being mediated through cholinergic cells in the region (Fitzgerald and Proudfit, 1989). The involvement of the PPTg in both antinociception and forward locomotion 
supports Garcia-Rill's (1991) suggestion that, in the process of forward locomotion, it may be advantageous and possibly necessary to suppress sensory input.

over twenty years ago, Glickman and Schiff (1967) observed that a fundamental characteristic of natural rewards is their ability to induce species typical approach behaviours. Because of this association, they proposed that neural substrates of reinforcement and forward locomotion are closely related. Consistent with this hypothesis, the evidence outlined above indicates that a single neural region, the PPTg, is involved in both the reinforcing effect of natural rewards and the initiation of forward locomotion. Furthermore, forward locomotion elicited by PPTg stimulation appears to be mediated through the VTA-NA-VP-PPTg pathway which is associated with reinforcement: First, locomotor activity can be induced by amphetamine or DA injections into the NA, whereas lesions, inactivation, or blockage of synaptic transmission in the PPTg reduce the effect (Brudzynski and Mogenson, 1985; Mogenson et a1., 1990). Second, picrotoxin injections into the VP induce locomotion; inactivation of the PPTg reduces the effect (Mogenson and Wu, 1988). Third, blocking the VP-PPTg pathway reduces locomotion induced by picrotoxin injections in the VP and amphetamine injections in the NA (Mogenson et al., 1985).

Based on anatomical evidence linking the PPTg to 1 imbic and motor systems, Mogenson et al. (1980) propose that this 
region is strategically situated to contribute to the locomotor component of adaptive behaviours; Bechara and van der kooy (1989) agree that reward information exiting the limbic system influences appetitive behaviour in the region of the PPTg. Both proposals suggest that limbic structures associated with biologically significant behaviours transmit motivational signals to the PPTg, which projects to motor systems in order to initiate locomotion (Mogenson, 1987). Because previous studies associate the PPTg with the initiation of forward locomotion, results from the present study which confirms that the PPTg is also involved in reinforcement provide further support for the hypothesis that reinforcement and forward locomotion are mediated through the same neural substrate.

In conclusion, the present study was undertaken as a continuation of previous work which examined the relationship between neural substrates of reinforcement and analgesia. The study confirmed the role of the PPTg in the development of a morphine-induced CPP, but showed that its role in the reinforcing effect of morphine was dissociable from the analgesic effect of moprhine. These results have important clinical implications in that they suggest that knowing where reinforcement and analgesia systems are integrated and where they diverge may provide clues for strategies to develop analgesic drugs with low abuse potential. 


\section{REFERENCES}

Abbott, F.V., Franklin, K.B.J., Ludwick, R.J., and Melzack, R. (1981). Apparent lack of tolerance in the formalin test suggests different mechanisms for morphine analgesia in different types of pain. Pharmacology. Biochemistry and Behavior, 15, 637-640.

Arbott, F.V., Grimes, R.W., and Melzack, R. (1984). Single nerve capsaicin: effects on pain and morphine analgesia in the formalin and foot-flick tests. Brain Research, 295, 77-84.

Abbott, F. V. and Melzack, R. (1982). Braiıstem lesions dissociate neural mechanisms of morphine analgesia in different kinds of pain. Brain Research, 251, 149-155.

Abbott, F.V. and Melzack, R. (1983). Dissociation of the mechanisms of stimulation-produced analgesia in tests of tonic and phasic pain. Advanced Pain Research Therapy, 5 , 401-409.

Abbott, F. V., Melack, R., and Samuel, C. (1982). Morphine analgesia in the tail-flick and formalin pain tests is mediated by different neural systems. Experimental Neurology, 75, 644-651.

Abbott, F.V. and Young, S.N. (1989). Effect of 5hydroxytryptamine precursors on morphine analgesia in the fcrmalin test. Pharmacology, Biochemistry and Behavior, 31, 855-860.

Alexander, G.E. and crutcher, M.D. (1990). Functional architecture of basal ganglia circuits: neural substrates of parallel processing. Trends in Neuroscience, 13.7. 266-271.

Antelman, S.M., Rowland, N.E., and Fisher, A.E. (1976). Stimulation bound ingestive behavior: a view from the tail. Science, 191, 310-312.

Antelman, S.M., Szechtman, H., Chin, P., and Fisher, A.E. (1975). Tail-pinched induced eating, grawing and licking behavior in rats: dependence on the nigro striatal dopamine systsm. Brain Research, 99, 319-337.

Bechara, A., Harrington, F., Nader, K., and van der Kooy, D. (1991). The neurobiology of motivation: double dissociation of two motivational mechanisms mediating opiate reward in drug naive versus drug dependent animals. (in press). 
Bechara, A. and van der Kooy, D. (1989). The tegmental pedunculopontine nucleus: a brain stem output of the limbic system critical for the conditioned place preferences produced by morphine and amphetamine. The Journal of Neuroscience, 9.10, 3400-3409.

Bechara, A. and van der Kooy, D. (1991a). Chronic exposure to morphine does not alter the neural tissues subserving its acute rewarding properties: apparent tolerance is overshadowing. Journal of Behavioral Neuroscience, (in press ).

Bechara, A. and van der Kooy, D. (1991b). Lesions of the tegmental pedunuculopontine nucleus: effects on the locomotor activity induced by morphine and amphetamine. Pharmacology, Biochemistry, and Behavior, (in press).

Bechara, A. and van der Kooy, D. (1991c). A single brainstem substrate mediates the motivational effects of buth opiates an food in non deprived, but not in deprived animals. Tournal of Behavioral Neuroscience, (in press).

Beebe-Center, J.G. (1932). The Psychology of Pleasantness and unpleasantness. New York: D. van Norstrand.

Beecher, H.K. (1959) - Measurements of Subjective Responses: Quantitative Effects of Drugs (pp. 157-190). New York: oxford University Press.

Ben-Ari, Y., Tremblay, E., ottersen, O.P., and Meldrum, B.S. (1980). The role of epileptic activity in hippocampal and remote cerebral lesions induced by kainic acid. Brain Research, 191, 79-97.

Beninato, M. and spencer, R.F. (1987). A cholinergic projection to the rat substantia nigra from the pedunculopontine tegmental nucleus. Brain Research, 412, 169-174.

Blass, E., Fitzgerald, E., and Kehoe, P. (1987). Interactions between sucrose pain and isolation distress. Pharmacology, Biochemistry and Behavior, 26, 483-489.

Brudzynski, S.M., Houghton, P.E., Brownlee, R.D., and Mogenson, G.J. (1986). Involvement of neuronal cell bodies of the mesencephatic locomotor region in the initiation of locomotor activity of freely behaving rats. Brain Research Bulletin, 16, 377-381. 
Brudzynski, S.M. and Mogenson, G.J. (1985). Association of the mesencephalic locomotor region rith locomotor activiy induced by injections of amphetamine into the nucleus accumbens. Brain Research, 334, 77-84.

Buscher, W., Schugens, M., wagner, U., and Huston, J.P. (1989). Interhemispheric relationship between lateral hypothalamic self-stimulation and the region of the nucleus tegmenti pedunculo-pontinus. Brain Research, 487, 321-334.

Buxbaum, D.M., Yarbrough, G.G., and Carter, M.E. (1973). Biogenic amines and narcotic effects. 1. Modification of morphine-induced analgesia and motor activity after alteration of cerebral amine levels. Journal of Pharmacolgy and Experimental Therapeutics, 185, 317-327.

Carr, G.D., Fibiger, H.C., and Philips, A.G. (1989). Conditioned place preference as a measure of drug reward. In J.M. Lebiman and S.J. Cooper (Eds.), Oxford Reviews in Psycopharmacology (pp. 264-319). Oxford: Oxford University Press.

Carr, K.D. (1984). The physiology of opiate hedonic effects and the role of opioids in motivated behavior. Advances in Alcohol and substance Abuse, 3, 5-19.

Carr, K.D., and Coons, E.E. (1981). Rats self-administer nonrewarding brain stimulation to ameliorate aversion. Science, 215, 1516-1517.

Carroll, M.N. and Lim, R.K.S. (1960). Observations on the neuropharmacology of morphine and morphinelike analgesia. Archives International Pharmacodynamics, 75. 3-4, 383403 .

clarke, P.B.S., Hommer, D.W., Pert, A., and Skirboll, L.R. (1987). Innervation of substantia nigra neurons by cholinergic afferents from the pedunculopontine nucleus in the rat: Neuroanatomical and electrophysiological Evidence. Neuroscience, 23, 1011-1019.

Clarke, P.B.S., White, N.M., and Franklin, K.B.J. (1990) . 6Hydroxydopamine lesions of the olfactory tubercle do not alter ( $(+)$ amphetamine-conditioned place preference. Behavioural Brain Research, $36,185-188$.

clements, J.R. and Grant, S. (1990). Glutamate-1ike immunoreactivity in neurons of the laterodorsal tegunental and pedunculopontine nuclei in the rat. Neuroscience Letters, 120, 70-73. 
Cohen, R., Abbott, F.V., and Melzack, R. (1984). Unilateral analgesia produced by intraventricular morphine. Brain Research, 303, 277-287.

Cohen, S.R. and Melzack, R. (1985). Morphine injected into the habenula and the dorsal posteromedial thalamus produces analgesia in the formalin test. Brain Research, 359, 131139.

Cohen, S.R. and Melzack, R. (1986). Habenular stimulation produces analgesia in the formalin test. Neuroscience Letters, 70, 165-169.

Conrad, L.C.A., Leonard, C.M., and pfaff, D.W. (1974). Connections of the median and dorsal raphe nuclei in the rat: an autoradiographic and degeneration study. Journal of Comparative Neurology, 156, 179-206.

Costall, B. and Naylor, R.J. (1974). on catalepsy and catatonia and the predictability of the catalepsy test for neuroleptic activity. Psychopharmacologia, 34, 233241 .

Crow, T.J. (1972). A map of the rat mesencephalon for electrical self-stimulation. Brain Research, 36, 265-273.

Dellovade, T.L., Martin, L.J., Koliatsos, V.E., and Price, D.L. (1988). Cholinergic innervation of deep cerebellar nuclei from the pedunculopontine tegmental nucleus. Society for Neuroscience Abstracts, 14, 632 .

Dellu, R., Mayo, W., Cherkaoui, J., Le Moal, M., and Simon, H. (1991). Learning disturbances following excitotoxin lesion of cholinergic pedunculo-pontine nucleus in the rat. Brain Research, 5444, 126-132.

Dennis, S.G. and Melzack, R. (1980). Pain modulation by 5hydroxytryptamine agents and morphine as measured by three pain tests. Experimental Neurology, 69, 260-270,

Dennis, S.G., Melzack, R., Gutman, S., and Boucher, F. (1980). Páin modulation by adrenergic agents and morphine as measured by three pain test. Life Sciences, 26, 1247$125 \%$.

De witte, P. (1979). Compensatory effects of hypothalamic rewarding stimulation during cuncomitant painful footshock. Physiological Behavior, 22, 429-434. 
Dubuisson, D. and Dennis, S.G. (1977). The formalin test: a quantitative study of the analgesic effects of morphine, meperidine, and brain stem stimultion in rats and cats. Pain, 4, 161-174.

Fasmer, O.B., Berge, O.G., Tveiten, L., and Hole, K. (1986). Changes in nociception after 6-hydroxydopamine lesions of descending catecholaminergic pathways in mice. Pharmacology, Biochemistry and Behavior, 24, 1441-1444.

Fields, H.L., Heinricher, M.M., and Mason, P. (1991). Nerotransmitters in nociceptive modulatory circuits. In W.M. Cowan, E.M. Shooter, C.F. Stevens, and R.F. Thompson (Eds.), Annual Review of Neuroscience Vol. 14 (pp. 219245). California: Annual Reviews Inc.

Fitzgerald, C.F. and proudfit, H.K. (1989). Cholinergic mediation of antinociception produced by electrical stimulation of the pedunculopontine tegmentum. Society for Neuroscience Abstracts, 15, 151 .

Franklin, K.B.J. (1989). Analgesia and the neural suostrate of reward. Neurobiology and Behavioral Reviews, 13, 1-5.

Franklin, K.B.J. and Abbott, F.B. (1989). Techniques for assessing the effects of drugs on nociceptive responses. In $\dot{A} . A$. Boulton, G.B. Baker, and A.J. Greenshaw (Eds.), Neuromethods: Vol. 1. Psychopharmacology (pp. 145-216). clifton, NJ: The Humana Press Inc.

Garcia-Rill, E. (1986). The basal ganglia and the locomotor regions. Brain Research, 11, 47-63.

Garcia-Rill, E. (1991). The pedunculopontine nucleus. Progress in Neurobiology, 36, 363-389.

Garcia-Rill, E., Houser, C.R., skinner, R.D., Smith, W., and Woodward, D.J. (1987). Locomotion-inducing sites in the vicinity of the pedunculopontine nucleus. Brain Research, $18,731-738$.

Garcia-Rill, E., Kinjo, N., Atsuta, Y., Ishikawa, Y., Webber, M., and Skinner, R.D. (1990). Posterior midbrain-induced locomotion. Brain Research Bulletin, 24, 499-508.

Garcia-Rill, E., Skinner, R.D., Conrad, C., and Mosley, D. (1986). Projections of the mesencephal ic locomotor region in the rat. Brain Research Bulletin, 17, 33-40.

Garcia-Rill, E., Skinner, R.D., and Fitzgerald, J.A. (1983). Activity in the mesencephalic locomotor region during locomotion. Exploratory Neurology, 82, 609-622. 
Garcia-Rill, E., Skinner, R.D., and Fitzgerald, J.A. (1985). Chemical activation of the mesencephalic locomotor region. Brain Research, 330, 43-54.

Glickman, S. and Schiff, B. (1967). A biological theory of reinforcement. Psychological Review, 24.2. 81-109.

Goldsmith, M. and van der Kooy, D. (1988). Separating noncholinergic descending projections and cholinergic ascending projections from tho nucleus tegment 1 pedunculopontinus. Brain Research, 415, 386-391.

Graybiel, A. and Ragsdale, C.W. (1978). Fiber connections of the basal ganglia. Progress in Brain Research, 51, 239283.

Hallanger, A.E., Levey, A.I., Lee, H.J., Rye, D.B., and wainer, B.H. (1987). The origins of cholinergic and other subcortical afferents to the thalamus in the rat. The Journal of Comparative Neurology, 262, 105-124.

Hammond, C., Rouzaire-Dubois, B., Feger, J., Jackson, A., and Crossman, A.R. (1983). Anatomical and electrophysiological studies on the reciprocal projections between the subthalamic nucleus tegmenti pedunculopontinus in the rat. Neuroscience, 9, 41-52.

Hand, T. and Franklin, K.B.J. (1985). Lesions of the ventral tegmental dopamine neurons delay the development of tolerance to morphine catalepsy. Neuroscience Letters, 55, $367-370$.

Haws, C.M., Williamson, A.M., and Fields, H.L. (1989). Putative nociceptive modulatory neurons in the dorsolateral pontomesencephalic reticular formation. Brain Research, 483, 272-282.

Hubner, C.B. and Koob, G.F. (1987) Ventral pallidal lesions produce decreases in cocaine and heroin self administration in the rat. Society for Neuroscience Abstracts, 13, 1717 .

Huston, J.P., Grimm, C., and Ornstein, K. (1984). Selfstimulation in the brain stem after ipsilateral precollicular decerebration. Experimental Neurology, 83, 568-576.

Jackson, A. and Crossman, A.R. (1983). Nucleus tegmenti pedunculopontinus: efferent connections with special reference to the basal ganglia, studied in the rat by anterograde and retrograde transport of horseradish peroxidase. Neuroscience, 10.3, 725-765. 
Jaffe, H.H. and Martin, W.R. (1975). Narcotic analgesics and antagonists. In L.S. Goodman and A. Gilman (Eds.), The Pharmacological Basis of Therapeutics (pp. 245-283). New York: Macmillan.

Jarrard, L.E. (1986). Selective hippocampal lesions and behavior. In Robert L. Isaacson and Karl H. Pribram (Eds.), The Hippocampus: Yol.4 (pp. 93-123). New York: Plenum press.

Kang, Y. and Kitai, S.T. (1990). Electrophysiological properties of pedunculopontine neurons and their postsynaptic responses following stimulation of substantia nigra reticulata. Brain Research, 535, 79-95.

Katayama, Y., DeWitt, D.S., Becker, D.P., and Hayes, R.I. (1984). Behavioral evidence for a cholinoceptive pontine inhibitory area: Descending control of spinal motor output and sensory input. Brain Research, 296, 241-262.

Koob, G.F. and Bloom, F.E. (1988). Cellular and molecular mechanisms of drug dependence. Science, 242, 715-723.

Lee, H.J., Rye, D.B., Hallaner, A.E., Levey, A.I., and Wainer, B.H. (1988). Cholinergic vs. noncholinergic efferents from the mesopontine tegmentum to the extrapyramidal motor system nuclei. The Journal of Comparative Neurology, 275, 469-492.

Le Magnen, J., Marfaing-Jallat, P., Miceli, D. , and Devos, M. (1980). Pain modulating and reward systems: A single brain mechanism? Pharmacology, Biochemistry and Behavior, $12,729-733$.

Levine, A.S., Wilcox, G.L., Grace, M., and Morley, J.E. (1982). Tail pinch induced consummatory behaviors are associated with analgesia. Physiological Behavior, 28, 959-962.

Lin, Y., Morrow, T.J., Kiritsy-Roy, J.A., Terry, L.C., and Casey, K.L. (1989). Cocaine: evidence for supraspinal, dopamine-mediated, non-opiate analgesia. Brain Research, $479,306-312$.

Marshall, J.G. and Teitelbaum, P. (1974). Further analysis of sensory inattention following lateral hypothalamic damage in rats. Journal of comparative and Phsyiological Psychology, $3,375-395$.

Matthies, B.K. and Franklin, K.B.J. (1990). Formalin pain but not analgesia in brainstem transected rats. Society for Neuroscience Abstracts, 16, 705. 
MCGivern, R.F. and Bentson, G.G. (1980). Mediation of diurnal fluctuation in pain sensitivity in the rat by food intake patterns: reversa] by naloxone. Science, 210, 210-211.

Mogenson, G.J. (1987). Limbic-motor integration. In: A.N. Epstein (Ed.), progress in Psychoblology and Physiological Psychology (Vol. 12, pp. 117-170). New York: Academic Press.

Mogenson, G.J., Jones, D.L., and Yim, C.Y. (1980). From motivation to action: Functional interface between the 1 imbic system and the motor system. Progress_in Neurobiology, 14, 66-97.

Mogenson, G.J. Swanson, L.W., and Wu, M. (1985). Evidence that projections from substantia innominata to zona incerta and mesencephalic locomotor regions contribute to locomotor activity. Brain Research, 334, 65-76.

Mogenson, G.J. and Wu, M. (1986). Subpallidal projections to the mesencephalic locomotor region investigated with a combination of behavioral and electrophysiological recording techniques. Brain Research Bulletin, 16, 383390 .

Mogenson, G.J. and Wu, M. (1988). Differential effects on locomrtor activity of injections of procaine into mediodorsal thalamus and pedunculopont ine nucleus. Brain Research Bulletin, 20, 241-246.

Mogenson, G.J., Wu, M., and Brudzynski, S.M. (1990). The role of the pedunculopontine nucleus in locomotor activity. Society for Neuroscience Abstracts, 16, 753.

Moon Edley, S. and Graybiel, A.M. (1983). The afferent and efferent connections of the nucleus tegmerti pedunculopontinus, pars compacta. The Journal of Comparative Neurology, 217, 187-215.

Morgan, M.J. and Franklin, K.B.J. (1990). 6-Hydroxydopamine lesions of the ventral tegmentum abolish D-amphetamine and morphine analgesia in the formalin test but not in the tail-flick test. Brain Research, 519, 144-149.

Morgan, M.J. and Franklin, K.B.J. (1991). Dopamine receptor subtypes and formalin test analgesia. Pharmacology. Biochemistry, and Behavior, (in press).

Mucha, R.F. and Iversen, S.D. (1985). Reinforcing properties of morphine and naloxone revealed by conditioned place preferences: A procedural examintion. Psychopharmacology, $82,241-247$. 
Mucha, R.F., van der Kooy, D., O'Shaughnessy, M., and Bucenieks, P. (1982). Drug reinforcement studied by use of the place conditioning in rat. Brain Research, 243, 91-105.

Nauta, W.J.H., Smith, G.P., Faull, R.L.M., and Domesick, V.B. (1978). Efferent connections and nigral afferents of the nucleus accumbens septi in the rat. Neuroscience, 3 , $385-401$.

Newman, D. (1985). Distinguising rat brainstem reticulospinal nuclei by the neuronal morphology. II. Pontine and mesencephalic nuclei. Journal Fur Hirnforschung, 26, 385418 .

Newman, D.B. and Ginsberg, C.Y. (1988). Nuclear origins of projections from the brain stem reticular formation to the cerebellum in the rat. Society for Neuroscience Abstracts, 14, 337 .

Olszewski, J. and Baxter, D. (1954). Cytoarchitecture of the Human Brain Stem. New York: 5 . Karger Inc.

Paxinos, G. and Watson, C. (1986). The Rat Brain in Stereotaxic Co-ordinates. London: Academic Press.

Pertovaara, A., Belczynski, C.R., Morrow, T.J., and Casey, K.L. (1988). The effect of systemic cocaine on spinal nociceptive reflex activity in the rat. Brain Research, 438, 286-290.

Petit, H.O., Ettenberg, A., Bloom, F.E., and Koob, G.F. (1984). Destruction of dopamine in the nucleus accumbens selectively attenuates cocaine but not heroin selfadministration in rats. Psychopharmacology, 84, 167-173.

Roane, D.S. and Martin, R.J. (1990). Continuous sucrose feeding decreases pain threshold and increases morphine potency. Pharmacology, Biochemistry and Behavior, 35, 225-229.

Roberts, D.C.S., Koob, G.F., Klonoff, P., and Fibiger, H.C. (1980). Extinction and recovery of cocaine selfadministration following 6-hydroxydopamine lesions of the nucleus accumbens. Pharmacology. Biochemistry, and Behavior, 12, 167-170.

Rompre, P.P. and Trudeau, L.E. (1991). Refractory period estimates of pedunculopontine cells driven by electrical stimulation of the medial forebrain bundle. IBRO Abstratcts, 151 . 
Ryan, S.M., Watkins, L.R., Mayer, D.J., and Maier, S.F. (1985). Spinal pain suppression mechanisms may dijefer for phasic and tonic pain. Brain Research, 334, 173-175.

Rye, D.E., Lee, H.J., Saper, C.B., and wainer, B.H. (1988). Medullary and spinal efferents of the pedunculopontine teqmental nucleus and adjacent mesopontine tegmentum in the rat. The Journal of Comparative Neurology, 269, 315341 .

Rye, D.B., Saper, C.B., Lee, H.J., and wainer, B.H. (1987). Pedunculopontine tegmental nucleus of the rat: Cytoarchitecture, cytochemistry, and some extrapyramidal connections of the mesopontine tegmentum. The Journa 1 of Comparative Neurology, 259, 483-528.

Saper, C.B. and Lowey, A.D. (1982). Projections of the pedunculopontine tegmental nucleus in the rat: evidence for additional extrapyramidal circuitry. Brain Research, $252,367-372$.

Scarnati, E., Di Loreto, S., Proia, A., and Gallıé, G. (1988). The functional role of the pedunculopontine nucleus in the regulation of the electrical activity of entopeduncular neurons in the rat. Archives Italiennes de Biologie, 126, 145-163.

Scarnati, E., Proia, A., Campana, E., and Pacitti, C. (1986). A microiontophoretic study on the nature of the putative synaptic neurotransmitter involved in the pedunculopontine-substantia nigra pars compacta excitatory pathway in the rat. Experimental Brain Research, $\underline{62}, 470-478$.

Skinner, R.D. and Garcia-Rill, E. (1984). The mesencephalic locomotor region in the rat. Brain Research, 323, 185189.

Spann, B.M. and Grofova, I. (1989). Origin of ascending and spinal pathways from the nucleus tegmenti pedunculopontinus in the rat. The Journal of Comparative Neurology, 283, 13-27.

Spencer, H. (1872). The Principles of Psychology. New York: Appelton-Century-Crofts.

Spyraki, C., Fibiger, H.C., and Phillips, A.G. (1982a). Cocaine-induced place preference conditioning: lack of effects of neuroleptics and 6-hydroxydopamine lesions. Brain Research, 253, 195-203. 
Spyraki, C., Fibiger, H.C., and Phillips, A.G. (1982b). Dopaminergic substrates of amphetamine-induced place preference conditioning. Brain Research, 253, 185-193.

spyraki, C., Fibiger, H.C., and Phillips, A.G. (1983). Attenuation of heroin reward in rats by disruption of the mesolimbic doapmine system. Psychopharmacology, 79, 278283 .

Sutherland, R.J. and S. Nakaijima. (1981). Self-stimulation of the habenular complex in the rat. Journal of Comparative and Physiological Psychology, 95, 781-791.

Swanson, L.W. (1982). The projections of the ventral tegmental area and adjacent regions: A combined fluorescent retrograde tracer and immunofluorescence study in the rat. Brain Research Bulletin, 9, 321-353.

Swanson, L.W., Mogenson, G.J., Gerfen, C.R., and Robinson, P. (1984). Evidence for a projection from the lateral preoptic area and substantia innominata to the 'mesencephalic region' in the rat. Brain Research, 295, $161-178$.

Swerdlow, N.R., Swanson, L.W., and Koob, G.F. (1984). Electrolytic lesions of the substantia innominata and lateral preoptic area attenuate the "supersensitive" locomotor response to apormophine from denervation of the nucleus accumbens. Brain Research, 306, 141-148.

Tchakarov, L., Abbott, F.V., Ramierz Gonzales, M.D., and Kunos, G. (1985). Clonidine's analgesic actions are reversible with naloxone in spontaneously hypertensive rats. Brain Research, 328, 33-40.

Troland, L.T. (1928). The Fundamentals of Human Motivation. New York: Nostrand.

van der Kooy, D. (1987). Place conditioning: a simple and effective method for assessing the motivational properties of drugs. In M.A. Bozarth (Ed.), Methods for Assessing the Reinforcing Properties of Abused Drugs (pp. 229-240). New York: Springer-Verlag.

Vincent, S.R., Satoh, K., Armstrong, D.M., and Fibiger, H.C. (1983). NADPH-diaphorase: a selective histochemical marker for the cholinergic neurons of the pontine reticular formation. Neuroscience Letters, 43, 31-36.

Wise, R.A. (1988). The neurobiology of craving: implications for the understanding and treatment of addiction. Journal of Abnormal Pyschology, 97.2, 118-132. 
Wise, R.A, and Bozarth, M.A. (1987). A psychomotor stimulant theory of addiction. Psychological Review, 94, 469-492.

Zito, K.A., Vickers, G., and Roberts, D.C.S. (1985). Disruption of cocaine and heroin self-administration following kainic acid lesions of the nucleus accumbens. Pharmacology, Biochemistry, and Behavior, 23, 1029-1036. 